Review Article

\title{
Mucopolysaccharidoses I and II: Brief Review of Therapeutic Options and Supportive/Palliative Therapies
}

\author{
Haiyan Nan $(\mathbb{D}$, Chanbum Park $(\mathbb{D}$, and Sungho Maeng $(\mathbb{D}$ \\ Graduate School of East-West Medical Science, Kyung Hee University, Yongin, Gyeonggi-do 17104, Republic of Korea \\ Correspondence should be addressed to Sungho Maeng; jethrot@hotmail.com
}

Received 20 August 2020; Revised 8 November 2020; Accepted 21 November 2020; Published 4 December 2020

Academic Editor: Valeria D'Argenio

Copyright (C) 2020 Haiyan Nan et al. This is an open access article distributed under the Creative Commons Attribution License, which permits unrestricted use, distribution, and reproduction in any medium, provided the original work is properly cited.

\begin{abstract}
Purpose. Mucopolysaccharidoses (MPS) are group of inherited lysosomal storage diseases caused by mutations of enzymes involved in catalyzing different glycosaminoglycans (GAGs). MPS I and MPS II exhibit both somatic and neurological symptoms with a relatively high disease incidence. Hematopoietic stem cell therapy (HSCT) and intravenous enzyme replacement therapy (ERT) have had a significant impact on the treatment and comprehension of disease. This review is aimed at providing a comprehensive evaluation of the pros and cons of HSCT and ERT, as well as an up-to-date knowledge of new drugs under development. In addition, multiple disease management strategies for the uncontrollable manifestations of MPS I and MPS II to improve patients' quality of life are presented. Findings. Natural history of MPS I and MPS II shows that somatic and neurological symptoms occur earlier in severe forms of MPS I than in MPS II. ERT increases life expectancy and alleviates some of the somatic symptoms, but musculoskeletal, ophthalmological, and central nervous system (CNS) manifestations are not controlled. Additionally, life-long treatment burdens and immunogenicity restriction are unintended consequences of ERT application. HSCT, another treatment method, is effective in controlling the CNS symptoms and hence has been adopted as the standard treatment for severe types of MPS I. However, it is ineffective in MPS II, which can be explained by the relatively late diagnosis. In addition, several factors such as transplant age limits or graft-versus-host disease in HSCT have limited its application for patients. Novel therapies, including BBB-penetrable-ERT, gene therapy, and substrate reduction therapy, are under development to control currently unmanageable manifestations. BBB-penetrable-ERT is being studied comprehensively in the hopes of being used in the near future as a method to effectively control CNS symptoms. Gene therapy has the potential to "cure" the disease with a one-time treatment rather than just alleviate symptoms, which makes it an attractive treatment strategy. Several clinical studies on gene therapy reveal that delivering genes directly into the brain achieves better results than intravenous administration in patients with neurological symptoms. Considering new drugs are still in clinical stage, disease management with close monitoring and supportive/palliative therapy is of great importance for the time being. Proper rehabilitation therapy, including physical and occupational therapy, surgical intervention, or medications, can benefit patients with uncontrolled musculoskeletal, respiratory, ophthalmological, and neurological manifestations.
\end{abstract}

\section{Introduction}

Mucopolysaccharidoses (MPS) are rare, heterogeneous group of lysosomal storage disorders caused by a deficiency of various catalyzing enzymes that break down polysaccharides, called glycosaminoglycans (GAGs). GAGs are ubiquitously present in the connective tissue and play important roles in cell growth and proliferation, cell surface binding, and histamine storage [1-6]. GAGs are classified by their different core disaccharide structures into dermatan sulfate (DS), heparan sulfate (HS), keratan sulfate (KS), and chon- droitin sulfate (CS). DS is the main constituent of conjunctive tissues; $\mathrm{HS}$ is a major component of cellular membranes; KS and CS are major component of the cartilage and cornea [7].

After Charles Hunter and Gertrud Hurler first reported MPS in patients in 1917 and 1919, with the metabolic disorders now bearing their names (MPS I: Hurler syndrome, MPS II: Hunter syndrome), subsequent MPS types have been assigned numbers and eponyms loosely associated with the chronology and origin of their report [8]. Eleven enzymatic deficits are known to be responsible for seven different types 
of MPS along with the identification of the gene mutations responsible for the disease in the 1970s [9]. Each MPS disorder is caused by a deficiency in the activity of a single, specific lysosomal enzyme required for GAG degradation [10]. See Figure S1 and Table S1 in the Supplementary Materials for the stepwise degradation of the main GAG chains and defective enzymes and accumulated GAG for each type of MPS.

The majority of MPS is inherited in an autosomal recessive manner, except for MPS II, which is an X-linked recessive disease $[11,12]$. The incidence of overall MPS is approximately $1: 25,000$ births, and it varies between different MPS types. The estimated incidence of MPS I is $0.69-$ 1.66 per 100,000 live births, while the incidence of MPS II is $0.30-0.71$ per 100,000 live births worldwide [13-21]. The incidence rate has not been calculated for MPS IX because only four cases have been reported so far worldwide. MPS incidence also shows regional differences. The incidence of MPS I and MPS III is higher in European countries, whereas MPS II is the most prevalent type in Asian countries, including Japan, South Korea, China, and Taiwan [16, 22-26]. In South Korea and Japan, MPS II accounts for more than $50 \%$ of all MPS types, followed by MPS I and MPS III [24, 27]. In Denmark and Norway, MPS I is the most common type, which accounts for $30 \%$ and $60 \%$ of MPS patents, respectively $[10,22]$.

GAG accumulation in various tissues and organs leads to a wide spectrum of clinical manifestations and high progression rates within MPS types [13]. Somatic manifestations of MPS may include coarse facial features, hepatosplenomegaly, obstructive and restrictive respiratory disease, cardiac valve disease, musculoskeletal abnormalities, impaired vision, and dental abnormalities. These somatic symptoms are found in MPS types I, II, IV, VI, and VII [13, 28, 29]. Neurological symptoms with clinical features of aggressive, hyper/overactive behavior, developmental delay, and cognition decline are observed in patients with MPS I, II, III, and VII, the types associated with HS accumulation [30-32].

These lysosomal enzyme deficiencies are biochemically characterized by increased GAG concentration in urine, blood, and cerebral spinal fluid [33]. The diagnosis of MPS starts with the assessment of GAG in the urine (qualitative and quantitative) in suspected patients. A positive result is very suggestive of an MPS, but false-negative results are common. A confirmative diagnosis requires an enzyme activity assay in leukocytes, fibroblasts, dried blood spots, or plasma using substrates specific for the enzyme deficient in each MPS type, followed by further clinical, molecular, and biochemical analyses [9]. Given the clinical heterogeneity and progressive worsening characteristics of the MPS, it is important to establish a diagnosis as early as possible to initiate intervention before irreversible damage occurs. Due to the crucial role of early detection, the necessity of newborn screening has been raised. A direct multiplex assay of lysosomal enzymes in dried blood spots on filter paper by use of tandem mass spectrometry and a multiplexed immunequantification assay of lysosomal proteins from dried blood spots on filter paper have been developed in 2006 [34, 35]. In addition, a high-throughput multiplex method with high-performance liquid chromatography-tandem mass spectrometry to simultaneously assay several lysosomal enzymes for MPS in blood samples has been developed in the year 2013 [36]. IDUA enzyme activity screening in newborns is currently being performed as an initial pilot program in the United States, Taiwan, Italy, Austria, and Hungary [37-41].

MPS I and MPS II are the MPS types that display both somatic and neurological symptoms (including neurocognitive retardation and development delay) and exhibit relatively high incidence rate. For these reasons, MPS I and MPS II are chosen to provide the most recent knowledge on disease management. This paper reviews the appearance and progression of neurological, musculoskeletal, and ocular signs and symptoms in patients with MPS I and MPS II with a specific focus on disease treatment and management. It evaluates emerging therapies targeting uncontrolled manifestations of MPS, including blood-brain barrier- (BBB-) penetrable ERT, substrate reduction therapy (SRT), and gene therapy. Furthermore, it demonstrates the application of supportive/palliative therapies, such as physical and occupational therapy, hydrotherapy, surgical intervention, and medications which control the unmanageable symptoms associated with the musculoskeletal, respiratory, optical, and neurological symptoms of MPS.

\section{Results and Discussion}

2.1. Natural History of MPS I and MPS II. MPS I is an autosomal recessive disorder caused by the deficiency of $\alpha$-Liduronidase (IDUA), the lysosomal enzyme required for the degradation of DS and HS. This enzyme deficiency leads to HS and DS accumulation in the lysosomes of cells and extracellular tissues and organs. At least 257 variations have been identified with poor genotype/phenotype correlation [9]. Homozygosity or compound heterozygosity for two common nonsense mutations, p.W402X and p.Q70X, predominates among severe phenotypes, whereas p.P533R is associated with an intermediate-to-severe phenotype [37, 42]. Typically, MPS I has been classified into three phenotypes: Hurler syndrome, Hurler-Scheie syndrome, and Scheie syndrome. Hurler syndrome is the most severe form of the three phenotypes, whereas Scheie syndrome is the mildest $[43,44]$. The varying degrees of residual enzyme activity and GAG accumulation throughout the body result in a wide spectrum of disease manifestations and severity.

Table 1 summarizes the prevalence and onset time of clinical symptoms in Hurler syndrome [30, 45-51]. Coarse facial features, corneal clouding, hepatosplenomegaly, kyphosis/scoliosis, and cardiac valve disease are the most common symptoms in Hurler syndrome, occurring in $86.4 \%, 70.9 \%, 70.0 \%, 70.0 \%$, and $48.9 \%$ of the patients, respectively. The median age at each symptom onset is 0.9 years, 1.1 years, 1.1 years, 1.0 years, and 1.3 years, respectively $[45,46]$. Hurler syndrome is associated with significant developmental delay and cognitive impairment. Because the symptoms occur shortly after birth and progress rapidly, most Hurler patients die within the first decade of life. Conversely, Scheie syndrome has typically milder symptoms, 
TABle 1: Prevalence and onset age of typical manifestations in severe type MPS I and MPS II.

\begin{tabular}{|c|c|c|c|c|}
\hline \multirow{2}{*}{ Clinical symptoms } & \multicolumn{2}{|r|}{ MPS I } & \multicolumn{2}{|r|}{ MPS II } \\
\hline & Prevalence & Onset years of age ${ }^{*}$ & Prevalence & Onset years of age * \\
\hline Coarse face & $86.4 \%$ & 0.9 years & $95 \%$ & 2.4 years \\
\hline Hepatosplenomegaly & $70.0 \%$ & 1.1 years & $89 \%$ & 2.8 years \\
\hline Hernias & $58.9 \%$ & 0.8 years & $78 \%$ & 1.3 years \\
\hline Airway abnormalities ${ }^{\dagger}$ & $41 \%$ & 1.2 years & $70 \%$ & 3.4 years \\
\hline Cardiac valve disease & $48.9 \%$ & 1.3 years & $57 \%$ & 6.1 years \\
\hline \multicolumn{5}{|l|}{ Skeletal disorder } \\
\hline Joint contractures & $37.9 \%$ & 1.6 years & $84 \%$ & 3.6 years \\
\hline Kyphosis/scoliosis & $70.0 \%$ & 1.0 years & $33.8 \%$ & 6.4 years \\
\hline Dysostosis multiplex & $44 \%$ & 1.0 years & $8.6 \%$ & N/A \\
\hline Spinal stenosis & N/A & N/A & $46 \%$ & 14.3 \\
\hline \multicolumn{5}{|l|}{ Ocular manifestation } \\
\hline Corneal clouding & $70.9 \%$ & 1.1 years & & N/A \\
\hline Retinopathy & $80 \%$ & 10 years & Not common & $<21$ years \\
\hline Glaucoma & $10 \%$ & 1 years & & 7.5 years \\
\hline \multicolumn{5}{|l|}{ Neurological disorder } \\
\hline Seizure & $29 \%$ & N/A & $18 \%$ & 9.3 years \\
\hline Carpal tunnel syndrome & $7.8 \%$ & 2.3 years & $25 \%$ & 7.9 years \\
\hline Brain abnormalities $^{\dagger \dagger}$ & NR & Most are evident at $<2$ years & NR & 6.0 years $^{* *}$ \\
\hline Cognition impairment & $46.4 \%$ & $\begin{array}{l}1.2 \text { years } \\
\text { Plateaus at } 3 \text { years, then decline }\end{array}$ & $100 \%$ & $\begin{array}{l}3.2 \text { years } \\
\text { Plateaus at } 4 \text { years, then decline }\end{array}$ \\
\hline Behavioral problem & $65 \%$ & $\mathrm{~N} / \mathrm{A}$ & $73 \%$ & $\begin{array}{l}\text { Hyperactive and aggressive } \pm 4 \text { years } \\
\text { Sleeping problems } 4.3 \text { years }\end{array}$ \\
\hline
\end{tabular}

${ }^{*}$ Given ages represent approximants of median ages in rapidly progressing MPS types, unless indicated otherwise. ${ }^{* *}$ Given as mean ages; ${ }^{\dagger}$ airway disease due to enlarged tongue, tonsils, and restrictive lung disease caused by inefficient mechanical properties of the chest. ${ }^{\dagger \dagger}$ Brain abnormalities include symptoms of hydrocephalus, ventriculomegaly, enlargement of perivascular spaces, and atrophy.

slower disease progression, and late onset symptoms, typically between the ages of 3 and 7 years. Although patients with Scheie syndrome usually develop significant diseaserelated morbidities, they still have normal cognitive function and will likely survive into adulthood. Hurler-Scheie syndrome is an intermediate phenotype characterized by mildto-no cognitive impairment but it exhibits somatic symptoms that reduce life expectancy into the second or third decade of life [46].

MPS II is an X-linked lysosomal storage disorder caused by deleterious mutations in the iduronate-2-sulfatase (I2S) gene. Enzyme deficiency results in the lack of degradation of DS and HS and therefore their progressive accumulation throughout the body. To date, 628 variations of I2S have been identified. Among them are missense/nonsense variants, which represent about $50 \%$ of cases, and small deletions, which represent about $29 \%$ of cases $[9,24]$. A few recurrent mutations, such as G374G, R443X, L522P, and recombination mutations, are found in MPS II patients [24, 52].

The clinical presentations of MPS II lie in wide spectrum of symptoms, from the most severe symptom to the mildest symptoms. Approximately two-thirds of patients with severe cases of MPS II exhibit neuropathic symptoms. Table 1 summarizes the prevalence and onset time of clinical symptoms in the severe form of Hunter syndrome [30, 45, 47, 48, 5358]. This severe type shows developmental delay and cognitive impairment, which becomes apparent at 3.2 years of age, followed by a rapid decline that becomes apparent from 4 years of age. The severe form of the disease progresses rapidly, and most patients die in their twenties $[42,59]$. Coarse facial features, hepatosplenomegaly, airway diseases, joint contractures, behavior problems, and cognition impairment are the most common symptoms in Hunter syndrome, occurring in 95\%, $89 \%, 70 \%, 84 \%, 73 \%$, and $100 \%$ of patients, respectively. The median ages of symptom onset are 2.4 years, 2.8 years, 3.4 years, 3.6 years, 4 years, and 3.2 years, respectively $[45,46]$. The mild type of Hunter syndrome is more likely to have somatic symptoms without cognitive impairment. However, other neurological symptoms including seizures or myelopathy may occur in these patients. The mild type has delayed symptom onset, and patients usually live into adulthood [42, 59].

Natural history of severe types of MPS I and II demonstrates that pathological progression occurs much faster in MPS I than MPS II because both somatic and central nervous system (CNS) symptoms occur relatively later in MPS II. Additionally, MPS I and MPS II symptoms exhibit different patterns. While ocular manifestations (corneal clouding and retinopathy) are uncommon in MPS II, they occur in about $80 \%$ of MPS I patients. Joint contraction is more frequent in MPS II ( $84 \%$ prevalence) than in MPS I (38\% prevalence). Kyphosis/scoliosis is more prevalent in MPS I than in MPS II, occurring in $70 \%$ and $39 \%$ of patients, respectively. 
Despite the fact that early and accurate diagnosis in MPS patients is highly important, data from the MPS I registry reveals a delay between symptom onset and disease diagnosis. In Hurler syndrome, initial symptoms occur at a median age of 6 months, but patients only receive an initial diagnosis at a median age of 12 months. Patients with Hurler-Scheie and Scheie syndromes show first symptoms sometimes after infancy, and there is a 2- to 4-year gap between symptom onset and diagnosis [46]. Data from the MPS II registry shows that the median age of symptom onset is at 1.5 years, but the syndrome diagnosis is at 3.5 years. This shows an approximate two-year delay between symptom onset to diagnosis in Hunter syndrome [53]. The lag in symptom onset and diagnosis time may be due to the rarity of the disease, variability in clinical presentation, different disease progression states, and the nonspecific nature of some of the initial manifestations of the disease.

2.2. Current Therapies: Efficacy and Limitations. Over the last few decades, there has been considerable development in the availability of disease-specific treatments. Nowadays, therapies for MPS I and MPS II involve hematopoietic stem cell therapy (HSCT) and intravenous enzyme replacement therapy (ERT), which have had a significant impact on the treatment and comprehension of disease. After the introduction of HSCT and ERT, the natural history of MPS I and MPS II has changed significantly [60].

2.2.1. Hematopoietic Stem Cell Therapy. Hematopoietic stem cells are created in the bone marrow and are also found in peripheral blood and umbilical cord blood. After undergoing immunosuppressive therapy to deplete patient's immune response, the patient receives healthy matched donor cell transplant, and the enzymes are secreted from the donor cell [61]. HSCT may provide a permanent source of the missing enzyme by engrafted donor-derived hematopoietic stem cells. Additionally, HSCT enables the engraftment of donor-derived microglial cells to produce the deficient enzyme in the brain locally. This treatment, which is different from the intravenous administration of enzymes, may be effective in treating CNS manifestations [62]. HSCT needs to be performed only once, and the effect has long-lasting benefits for both cognitive function and physical symptoms $[63,64]$. After the first successful bone marrow transplant in 1980, approximately 600 patients with a severe phenotype of MPS I have received HSCT [61, 65]. HSCT has been reported to prevent many of the clinical symptoms of MPS I, VI, and VII [66-69]. It can alleviate symptoms of growth, endurance, hepatosplenomegaly, joint mobility, upper airway obstruction, and respiratory function, but it shows a limited effect on existing skeletal dysplasia and cardiovascular abnormalities $[43,70]$. One recent study showed that the overall survival rate of patients with Hurler syndrome undergoing HSCT at 1 year and 20 years was the same at $73.7 \%$. Meanwhile, another study reported that the survival rates at 1 year and 25 years were $70 \%$ and $37 \%$, respectively [ 71 , 72]. This implies a reduced mortality rate and increased life expectancy in MPS I patients received HSCT.
HSCT possesses the advantage of only having to be performed once with life-long effect of continuous enzyme provision from donor stem cells. However, the success of HSCT depends on many factors including the transplantation age, cardiopulmonary status, type of donor, and the ability to achieve stable engraftment without the development of graft-versus-host disease [73]. Hematopoiesis provides a variable enzyme level, thus differing HSCT efficacy in individual patients $[74,75]$. Furthermore, transplantation procedures performed too late may be unsuccessful in treating preexisting damage [76]. Although HSCT may improve clinical manifestations of the disease, it does not seem to correct these manifestations entirely and does not affect preexisting cognitive impairment. Meanwhile, HSCT is not able to cure symptoms in the bone or cornea due to insufficient delivery of enzymes to the sites [43, 70]. Therefore, HSCT is reserved for patients below the age of 2.5 with the most severe type of MPS and constitutes the standard care for treating severely affected MPS I patient with a developmental quotient $>70 \%$ of the normal, with an increased likelihood of maintaining cognitive abilities with early intervention [66]. Pretransplant ERT is recommended after diagnosis and before HSCT to optimize organ function and reduce morbidity and mortality [77].

It is noted that HSCT is not recommended for MPS II, which is the type that possesses similar clinical presentation of both somatic and neuropathic symptoms as MPS I. This is due to the fact that previous data has found no evidence of neurocognitive stabilization [78]. The difference effect of HSCT in MPS I and MPS II may be explained by the different times of diagnosis, with earlier diagnosis of MPS I as early as 12 months and relatively late diagnosis of MPS II at 3.5 years. Because HSCT can preserve intellectual development for most children-who would otherwise develop severe cognitive impairment-if applied early [67], it may also benefit MPS II patients receiving early diagnosis with newborn screening in the future.

2.2.2. Enzyme Replacement Therapy. ERT is the regular administration of genetically engineered enzymes obtained through recombinant DNA technology, which is a method to compensate for the defective enzyme. Infused enzymes are taken up by the cells into the lysosomes to catalyze accumulated GAGs, which finally lead to symptom resolution. ERT regimen involves the intravenous infusion of the recombinant human enzyme weekly or every other week. Currently, ERT has been developed for patients with MPS I and MPS II: laronidase (Aldurazyme ${ }^{\circledR}$, BioMarin) was approved in 2003 for MPS I [79, 80], and idursulfase (Elaprase ${ }^{\circledR}$; Shire Human Genetic Therapies, recently acquired by Takeda Pharmaceutical) and idursulfase-beta (Hunterase $^{\circledR}$, GC Pharma) were approved in 2006 and 2012 for MPS II $[24,81,82]$. ERT has benefited patients in terms of improving joint mobility, walking ability, and pulmonary and respiratory functions, while also reducing spleen and liver volume in confirmatory clinical trials [83]. Some studies have reported that ERT increased the patient survival rate [84]. 
Generally, ERTs for MPSs have an acceptable safety profile and have benefited patients in alleviating several symptoms. However, the following factors have limited ERT application for MPS patients. First, the human body recognizes ERT as "foreign" and thus produces antibodies upon drug administration that may neutralize the ERT effect and induce life-threatening anaphylactic drug allergy. Up to $90 \%$ of the patients with MPS I and $50 \%$ of the patients with MPS II experience an initial infusion reaction, which can be resolved after months with antipyretics and/or antihistamines [85].

Second, ERT is burdensome for the patients and their families due to the life-long requirement of weekly or biweekly intravenous administration. Furthermore, although annual cost for ERT differs slightly depending on the country, it is quite expensive, which makes it unaffordable to many patients. One report indicated that the annual cost of ERT for an MPS I patient is $£ 258,201$ for an adult and $£ 139,563$ for a child, whereas it is $£ 537,605$ for an adult and $£ 314,004$ for a child with MPS II [86]. Although many countries, such as the United States, UK, Japan, South Korea, Brazil, Russia, and Malaysia, cover ERT cost via national reimbursement or national tender system, there are still many countries where patients have to pay out of pocket for the treatments, therefore, restricting the accessibility of ERT.

Last but not least, although many patients present neuropathic symptoms and are classified as severe type of MPS, ERT does not work for these patients, and it is thus regarded as "partial cure" treatment. Meanwhile, ERT shows little effect on joint/skeletal symptoms, heart valve disease, and corneal opacity $[12,48,60,62,83,87,88]$. These observations can be explained by two reasons. First, the high-molecular weight enzymes cannot easily penetrate the bone, cartilage, or $\mathrm{BBB}$ via intravenous (IV) administration. Moreover, injected enzymes are less effective in ocular pathologies due to the retina-brain barrier and the avascular nature of the cornea [84]. Secondly, the expression level of the mannose6-phosphate (M6P) receptor, which transports enzymes into the cells and then into the lysosomes, varies in different tissues. While the expression level is high in the heart, lung, and kidney, they are low in the muscle and brain $[89,90]$. These observations may explain penetration problems at specific sites and limited effects on joint/skeletal symptoms, heart valve disease, optic symptoms, and neurologic symptoms. In these circumstances, the necessity of new therapeutic strategies has been raised.

2.3. Novel Therapies under Development. As previously mentioned, unmanaged manifestations of MPS I and MPS II include neuropathic CNS symptoms, musculoskeletal dysfunction, and ophthalmological disorders. Novel therapies that are aimed at curing the disease with the addition of supportive/palliative treatment are thoroughly evaluated in the following sections.

Several drugs that will hopefully address manifestations that do not respond well to ERT or HSCT are in the preclinical or clinical phases of development. Table 2 summarizes the new and promising drugs under development for MPS I and MPS II $[62,87,91,92]$. Most of the new therapies target the neuropathic symptoms by delivering enzymes or genes into the brain of patients with MPS I and MPS II. These approaches include (1) BBB-penetrable ERT, which modifies the ERT for BBB penetrability, (2) gene therapy, which corrects the defective gene in the genome by delivering functional genes via virus vector or genome editing technology, and (3) SRT, which reduces GAGs accumulation by decreasing their synthesis or increasing lysosome function.

2.3.1. BBB-Penetrable ERT. The BBB's control of vascular permeability is essential in preventing neurotoxic substances and microorganisms from invading the CNS. However, it impedes the delivery of high-molecular weight therapeutic agents into the brain. Due to the difficulties in BBB penetration of the IV-administered ERT, changing the administration routes or redesigning the enzymes that could penetrate into the BBB could be considered.

Clinical studies are exploring alternative administration routes, such as the intrathecal (IT) or intracerebroventricular (ICV) routes. A phase I clinical trial of iduronidase-IT administered in tandem with standard dual HSCT therapy with peritransplant intravenous ERT reported positive results in 2019 (ClinicalTrials.gov Identifier (NCT): NCT00638547) [25]. A group of patients with Hurler syndrome who received iduronidase-IT in addition to HSCT and ERT showed significant decreases in cerebrospinal fluid (CSF) opening pressure, markers of disease activity, and markers of inflammation [90]. A phase I/II clinical trial performed in a group of randomized MPS II patients administrated $1 \mathrm{mg}, 10 \mathrm{mg}$, and $30 \mathrm{mg}$ of idursulfase-IT monthly for 6 months along with idursulfase-IV weekly, reported 80 90\% GAG decrease in CSF in 2015 [89]. This promising result led to a phase II/III initiation with monthly administration of $10 \mathrm{mg}$ idursulfase-IT in tandem with idursulfaseIV weekly in order to determine the effect on neurodevelopmental status in patients with severe types of MPS II (NCT02055118). However, per Shire (SME-Medical Communications, August 2017), there was no difference in cognition between the idursulfase-IT treated group and the control group after 12 months of treatment. Currently, they are performing a 10-year extension study of the phase II/III to further evaluate idursulfase-IT for long-term safety and cognition impairment (NCT02412787). The efficacy of idursulfase-beta via ICV route to reduce HS content in the CSF was reported in the MPS II murine model in 2018 [93], and a phase I/II clinical study administering idursulfase-betaICV in combination with approved ERT-IV administration in 6 paediatric patients was completed in 2019 [87]. In April 2020, GC Pharma and Clinigen announced the submission of New Drug Application in Japan for idursulfase-beta-ICV after receiving the Orphan Drug Designation grant in March (Press Release, Clinigen, April 01, 2020). It is expected that these alternative routes of ERT administration will benefit patients with currently unmanaged CNS symptoms.

Another strategy to control the neurological symptoms is the modification of the enzymes for $\mathrm{BBB}$ penetrability. $\mathrm{BBB}$ penetration requires the enzymes to cross a physiological transport system localized within the BBB. This system is 
TABLE 2: New drug candidates target unmanaged manifestations in MPS I and MPS II.

\begin{tabular}{|c|c|c|c|c|c|c|c|}
\hline Strategy & Type & Drug name & Stage & Administration & Mode of action & Sponsor & Reference \\
\hline \multirow{9}{*}{$\begin{array}{l}\text { BBB-penetrable } \\
\text { ERT }\end{array}$} & \multirow{4}{*}{$\begin{array}{c}\text { MPS } \\
\text { I }\end{array}$} & Iduronidase-IT & $\mathrm{Ph} \mathrm{I}$ & IT & CNS administration & Shire & NCT00638547 \\
\hline & & AGT-181 & $\mathrm{Ph} \mathrm{I} / \mathrm{II}$ & IV & $\begin{array}{l}\text { Insulin receptor-mAb } \\
\text { conjugated enzyme }\end{array}$ & ArmaGen & NCT03053089 \\
\hline & & JR-171 & $\mathrm{Ph} \mathrm{I} / \mathrm{II}$ & IV & $\begin{array}{c}\text { Transferrin receptor-mAb } \\
\text { conjugated enzyme }\end{array}$ & $\begin{array}{c}\text { JCR } \\
\text { Pharmaceuticals }\end{array}$ & NCT04227600 \\
\hline & & GNeo-IDUA & Pre-IND & IV & GNeo-conjugated enzyme & $\begin{array}{c}\text { TEGA } \\
\text { therapeutics }\end{array}$ & {$[91] .$.} \\
\hline & \multirow{5}{*}{$\begin{array}{c}\text { MPS } \\
\text { II }\end{array}$} & Idursulfase-IT & $\mathrm{Ph}$ II/III & IT & CNS administration & Shire & NCT02055118 \\
\hline & & $\begin{array}{l}\text { Idursulfase- } \\
\text { beta-ICV }\end{array}$ & $\mathrm{Ph} \mathrm{I} / \mathrm{II}$ & ICV & CNS administration & GC Pharma & {$[87] .$.} \\
\hline & & JR-141 & $\mathrm{Ph}$ II/III & IV & $\begin{array}{l}\text { Transferrin receptor-mAb } \\
\text { conjugated enzyme }\end{array}$ & $\begin{array}{c}\text { JCR } \\
\text { Pharmaceuticals }\end{array}$ & NCT03568175 \\
\hline & & AGT-182 & $\mathrm{Ph}$ II & IV & $\begin{array}{l}\text { Insulin receptor-mAb } \\
\text { conjugated enzyme }\end{array}$ & ArmaGen & NCT02262338 \\
\hline & & DN-310 & $\mathrm{Ph} \mathrm{I} / \mathrm{II}$ & IV & $\begin{array}{l}\text { Transferrin receptor-mAb } \\
\text { conjugated enzyme }\end{array}$ & $\begin{array}{c}\text { Denali } \\
\text { therapeutics }\end{array}$ & NCT04251026 \\
\hline \multirow{4}{*}{ Gene therapy } & \multirow{2}{*}{$\begin{array}{c}\text { MPS } \\
\text { I }\end{array}$} & $\begin{array}{c}\text { RGX-111 } \\
\text { (AAV9-IDUA) }\end{array}$ & $\mathrm{Ph} \mathrm{I} / \mathrm{II}$ & ICS & $\begin{array}{c}\text { In vivo gene delivering with } \\
\text { AAV }\end{array}$ & Regenxbio & NCT03580083 \\
\hline & & $\begin{array}{l}\text { SB-318 (AAV- } \\
\text { ZFN) }\end{array}$ & $\mathrm{Ph} \mathrm{I/II}$ & IV & $\begin{array}{l}\text { ZFN mediated genome } \\
\text { editing }\end{array}$ & $\begin{array}{l}\text { Sangamo } \\
\text { therapeutics }\end{array}$ & NCT02702115 \\
\hline & \multirow{2}{*}{$\begin{array}{l}\text { MPS } \\
\text { II }\end{array}$} & $\begin{array}{l}\text { SB-913 (AAV- } \\
\text { ZFN) }\end{array}$ & $\mathrm{Ph} \mathrm{I} / \mathrm{II}$ & IV & $\begin{array}{l}\text { ZFN mediated genome } \\
\text { editing }\end{array}$ & $\begin{array}{l}\text { Sangamo } \\
\text { therapeutics }\end{array}$ & NCT03041324 \\
\hline & & $\begin{array}{c}\text { RGX-121 } \\
\text { (AAV9-IDS) }\end{array}$ & $\mathrm{Ph} \mathrm{I} / \mathrm{II}$ & ICS & $\begin{array}{c}\text { In vivo gene delivering with } \\
\text { AAV }\end{array}$ & Regenxbio & NCT03566043 \\
\hline \multirow{3}{*}{$\begin{array}{l}\text { Substrate } \\
\text { reduction } \\
\text { therapy }\end{array}$} & \multirow{3}{*}{$\begin{array}{l}\text { Pan- } \\
\text { MPS }\end{array}$} & Genistein & $\mathrm{Ph}$ III & Oral & $\begin{array}{l}\text { Reduces proteoglycan } \\
\text { biosynthesis }\end{array}$ & $\begin{array}{l}\text { Manchester } \\
\text { University }\end{array}$ & $\begin{array}{c}2013-001479- \\
18 \dagger\end{array}$ \\
\hline & & Odiparcil & $\mathrm{Ph}$ IIa & Oral & B4GalT7 decoy substrate & $\begin{array}{l}\text { Inventiva } \\
\text { Pharma }\end{array}$ & NCT03370653 \\
\hline & & $\begin{array}{l}\text { PIKFyve } \\
\text { inhibitor }\end{array}$ & Discovery & $\mathrm{N} / \mathrm{A}$ & $\begin{array}{c}\text { Enhance lysosomal gene } \\
\text { expression }\end{array}$ & Biomarin & $\begin{array}{c}\text { US } \\
2019 / 0249155 \dagger \dagger\end{array}$ \\
\hline
\end{tabular}

IT: intrathecal; IV: intravenous; ICV: intracerebroventricular; ICS: intracisternal; IC: intracerebral; AAV: adeno-associated virus; ZFN: zinc finger nuclease; IDS: iduronate-2-sulfatase; IDUA: alpha-1-iduronidase; B4GalT7: $\beta$-1,4-galactosyltransferase; PIKFyve: FYVE finger-containing phosphoinositide kinase; GNeo: guanidinylated form of neomycin; mAb: monoclonal antibody. ${ }^{\dagger}$ EU Clinical Trials Register number, ${ }^{\dagger \dagger}$ United States Patent Application Publication_ Pub. No.: US 2019/0249155 A1, Pub. Date: Aug. 15, 2019.

responsible for the transport of molecules from the blood to the brain. The BBB-penetrable ERT approach involves receptor-mediated transcytosis, a process by which several endogenous proteins (e.g., insulin, leptin, and transferrin) bind to their specific receptors on capillary endothelial cells of the brain to transport into the brain parenchyma. Enzymes fused with antibodies for these receptors are sufficient for endocytosis into the endothelial cells, and they are followed by exocytosis into the abluminal space in the brain. Accordingly, deficient enzymes in each MPS type can be delivered into the brain parenchyma via the blood within the vascular lumen to exert their efficacy towards the target neuron cells [87].

Each company has adopted different strategies to enhance BBB penetration. JCR Pharmaceuticals combined anti-human transferrin receptor antibodies with $\alpha$-L-iduronidase (Project Code: JR-171) or iduronate-2-sulfatase (Project Code: JR-141) to enable the BBB penetration via IV administration [87]. A phase I/II study of JR-171 weekly administration in MPS I patients is in progress
(NCT04227600). A phase I/II study of weekly administration of JR-141 in patients with MPS II (NCT03128593) reported HS and DS suppression in plasma and urine during a 4week treatment period with a significant decrease of HS in the CSF at the 3-week time point [92]. Currently, JCR is performing an open-label phase II/III study in MPS II patients in order to evaluate the safety and efficacy of JR-141 during a 1year treatment (NCT03568175). Another pharmaceutical company, ArmaGen Technologies, conjugated the antihuman insulin receptor antibody with $\alpha$-L-iduronidase (Project Code: AGT-181) and iduronate-2-sulfatase (Project Code: AGT-182) to enable sufficient enzyme delivery to the brain [87]. The results from a phase I/II clinical study of AGT-181 IV administration in MPS I children showed stabilization of the neurocognitive development quotient and cortical grey matter measurement after 52 weeks of treatment (NCT03053089, NCT03071341), [94]. A phase I safety and dose-finding study of AGT-182 weekly IV administration (NCT02262338) was completed in 2017, but the data yet to be published. Meanwhile, Denali Therapeutics combined 
the antibody binding site of anti-human transferrin receptors with IDS to increase brain uptake of enzyme (Project Code: DNL-310) and is performing a phase I/II trial in MPS II children with weekly DNL-310 IV administration over a 6month period (NCT04251026).

Apart from the receptor-mediated transcytosis strategy to penetrate the $\mathrm{BBB}$, another approach involves combining a chemical transporter with proteins to facilitate the transport of enzymes into the cells and lysosomes by binding to the cell-surface heparan sulfate receptors. TEGA Therapeutics conjugated recombinant enzyme with a carrier-a guanidinylated form of neomycin (GNeo). This carrier possesses a high affinity for cell-surface heparan sulfate proteoglycans and has the capacity to take up the macromolecular cargo through micropinocytosis, which enables enzyme delivery to lysosomes. As reported in MPS murine model in 2017, the intranasal delivery of GNeo-conjugated $\alpha$-L-iduronidase resulted in the reduction of GAG storage in the brain [91].

BBB-penetrable ERT is a promising strategy to control CNS symptoms, including cognitive impairment, developmental delay, behavior problems, and seizures, which are unmanaged by current ERT.

2.3.2. Gene Therapy. The concept of gene therapy is to provide a functional copy of the defective gene, which will permanently reside within the cells and slow or reverse the disease state. Considering each MPS type is a result of a single-gene mutation of the lysosomal enzyme, delivering the therapeutic gene into the cells of multiple organs will enable dramatic improvement throughout the body. A variety of gene therapies with different viral vectors, such as adenovirus (AV), adeno-associated virus (AAV), retrovirus $(\mathrm{RV})$, and lentivirus (LV), are under investigation in preclinical or clinical stages with different administration routes: systemic IV administration or direct administration into the CNS via intracerebral injection and intra-CSF injection [62]. AAV vectors have some advantages in terms of longterm gene expression and safety profile compared with other viral vectors. As AAV vector genomes exist as episomes in target cells and rarely integrate into the genome, there is a lower risk of integration into host cell genomes that lead to insertion mutagenesis and genotoxicity for AAV vectors than for RV or LV vectors, which integrate into host cell genomes and lead to insertion mutagenesis [61]. Among the identified AAV serotypes (serotypes 1 to 13 ) that show a unique pattern of tissue tropism, AAV serotype 9 (AAV-9) can access the CNS by receptor-mediated transcytosis across the endothelium of BBB [95]. Therefore, the AAV-9 vector is applied more frequently in gene therapy for MPS [61].

Regenxbio designed the AAV9 vector to deliver the $\alpha$-1iduronidase gene for the treatment of MPS I (Project Code: RGX-111) and the iduronate-2-sulfatase gene for the treatment of MPS II (Project Code: RGX-121). In order to provide a permanent source of the secreted enzyme within the brain cells, intracisternal administration of RGX-111 in a phase I/II clinical trial with MPS I children is in progress to evaluate the safety and explorative effect (NCT03580083). A phase I/II trial of RGX-121 is designed for paediatric patients with MPS II who have or are at high risk of developing neurocognitive effects (NCT03566043) [62]. In July 2020, Regenxbio reported that RGX-111 and RGX-121 were well tolerated following one-time intracisternal administration, and data from a single patient with RGX-111 implied encouraging biomarker activity and continued progression in neurocognitive development. (REGENXBIO, PR Newswire, July 08, 2020).

In addition, site-specific in vivo genome editing, which is the genetic engineering tool used to modify DNA or RNA sequences, is under investigation. Genome editing is enabled by zinc-finger nucleases (ZFN) or clustered regularly interspaced short palindromic repeats-associated protein 9 (CRISPR/Cas9). These techniques have been thoroughly studied recently [96]. The engineered nuclease generates double-strand breaks (DSBs) at the correct position in the genome, which are repaired through nonhomologous end joining or homologous recombination. Sangamo Biosciences is developing an IV ZFN therapeutic for genome editing delivered by AAV vectors to insert a correct copy of the $\alpha$ L-iduronidase gene or the iduronate 2-sulfatase gene into the genome of the patient's hepatocytes. The goal is to achieve life-long therapeutic production of the deficient enzyme for the treatment of MPS I (Project Code: SB-318) and MPS II (Project Code: SB-913). A phase I/II clinical trial designed to evaluate the safety and efficacy of SB-318 in three paediatric patients with MPS I (NCT02702115) and SB-913 in 9 paediatric patients with MPS II (NCT03041324) was initiated in 2017. However, a limited effect was observed in this study due to low transgene expression levels for both MPS I and MPS II (February 7, 2019/PRNewswire/Sangamo Therapeutics) $[61,62,97]$. It is hypothesized that delivering the defective genes directly into the brain via intracerebral or intra-CSF injection achieves better control over the neurological symptoms than systemic IV administration.

The approval of voretigene neparvovec-rzyl (Luxturna ${ }^{\mathrm{TM}}$, Spark Therapeutics), an AAV-2-vector that brings the correct copy of the RPE65 gene intended for the treatment of RPE65 mutation-associated retinal dystrophy, by the US Food and Drug Administration in December 2017, marked the beginning of a new era in medicine in which many inherited diseases will be corrected by gene therapy [98]. Gene therapy can control neurological and ophthalmic manifestations if engineered to target hard-to-reach systems such as the brain, bone, or eye by recombinant enzymes. Furthermore, in contrast to ERT which requires life-long weekly/biweekly injection with immunogenicity problems, gene therapy provides a one-time permanent treatment with permanent effect preservation. Although the risk of genotoxicity and lack of long-term safety are hurdles that need to be overcome, gene therapy is the most ideal strategy to benefit MPS patients in the future.

2.3.3. Substrate Reduction Therapy (SRT). SRT represents an alternative approach for the treatment of MPS. While ERT is aimed at eliminating GAG storage within the lysosomes, the goal of SRT is to partially inhibit or slow down the biosynthetic cycle and reduce substrate accumulation when the enzymes are malfunctioning. Miglustat (Zavesca ${ }^{\circledR}$, Actelion Ltd.), the first SRT for lysosome disorders that slows down the production of glycosphingolipids, was approved in the 
European Union in 2002 to treat adults with mild-tomoderate type I Gaucher disease who were considered unsuitable for ERT [99]. As a synthetic analogue of D-glucose, Miglustat functions as a competitive inhibitor of glucosylceramide synthase, which is an essential enzyme in most glycosphingolipids synthetic chain. Later in 2009, Miglustat was approved for treating progressive neurological complications in people with Niemann-Pick disease type C. Several other SRT drugs are under development in preclinical and clinical studies for MPS patients.

Genistein (4,5,7-trihydroexyisoflavone), a natural isoflavone purified from soybean, showed GAG storage reduction via tyrosine kinase inhibition in MPS I, II, III, VI, and VII fibroblast cells and early clinical studies on MPS [100-102]. However, an open-label study with 19 MPS III paediatric patients treated with $5 \mathrm{mg} / \mathrm{kg} /$ day of genistein for 1 year failed to demonstrate improvement in the disability scale [103]. A double-blinded, randomized placebo-controlled clinical trial involving 30 patients with MPS III treated with $10 \mathrm{mg} / \mathrm{kg} /$ day of genistein showed small reduction in urinary GAG excretion and plasma HS, but no change in behaviour or hair morphology [104]. A phase III, double blinded, randomised, and placebo controlled clinical trial with a high dose $(160 \mathrm{mg} / \mathrm{kg} /$ day $)$ of oral administrated genistein for 1 year, followed by 1 year of open-label genistein administration, was initiated in 2014 (EudraCT 2013-001479-18). The result was reported in 2018 with slightly lower HS level in CSF. However, it failed to show any clinical benefit in MPS III patients [61].

Currently, Inventiva Pharma is developing an orally administrable small molecule called Odiparcil for the treatment of several types of MPS. Odiparcil, the $\beta$-1,4-galactosyltransferase (B4GalT7) decoy substrate, modifies GAG synthesis and facilitates the production of soluble GAG that can be excreted in the urine. It inhibits the accumulation of CS and DS in patients with MPS I, II, IVA, VI, and VII [105]. A 26-week, double-blinded, randomized, placebocontrolled phase IIa clinical study in patients with MPS VI older than 16 years of age was completed in September 2019 (NCT03370653). It displayed a good safety profile and improvements in cardiac and lung function and corneal clouding for patients receiving Odiparcil (News \& Events, Inventiva, December 18, 2019). Following the positive results of a Phase IIa clinical study in adult patients, Inventiva is developing a phase I/II trial of Odiparcil in paediatric patients with MPS VI who are older than 5 years (News \& Events, Inventiva, February 03, 2020).

Concurrently, BioMarin is developing a PIKFyve (FYVE finger-containing phosphoinositide kinase) inhibitor, which activates TFEB (transcription factor EB, a master transcriptional regulator of lysosomal biogenesis), TFE3 (transcription factor E3), and MITF (microphthalmia-associated transcription factor), thus enhancing lysosomal gene expression for MPS and other lysosome disorders (United States Patent Application Publication_US 2019/0249155 A1, Aug. 15, 2019).

SRT drugs are small molecules that are orally administrated that can easily access every organ/tissue to relieve GAG storage and disease manifestation. With the advantage of being distributed throughout the body, including the cartilage, eye, and brain, SRT may exhibit promising results on organ/tissues that are poorly managed by ERT or HSCT. Meanwhile, SRT could be combined with other therapies that target different tissue and stages in different disease progression status. In contrast to ERT or HSCT, SRT drugs are noninvasive. As a result, it is expected that SRT could be applied as a good strategy to control the unmanageable manifestations of neurological, musculoskeletal, and ophthalmological symptoms in the near future.

2.4. Supportive and Palliative Therapies. Considering the limitations of HSCT and ERT as disease-specific treatments, the management of symptoms with regular monitoring and supportive or palliative treatment is of utmost importance for MPS patients. Current supportive and palliative therapies include (1) surgical interventions, (2) physical therapy or occupational therapy, and (3) medications. Table 3 summarizes the general management, including monitoring and treatment for uncontrolled symptoms of MPS I and MPS II $[48,59,78]$.

Surgical interventions are required for various systemic symptoms and physical disabilities. Patients with MPS typically undergo surgical intervention at a very young age. Repeated surgical interventions are common in MPS patients. Data from the MPS I Registry, an international observational database, shows that about $75 \%$ of MPS I patients undergo the first surgery at less than 5 years of age [106]. A median of 3 to 4 operations was reported per patient, and the surgery percentages that preceded diagnosis were $36 \%, 46 \%$, and $63 \%$ for patients with Hurler syndrome, Hurler-Scheie syndrome, and Scheie syndrome, respectively $[54,106]$. Data from Hunter Outcome Survey, the multicenter observational database of MPS II, demonstrated that surgical interventions were performed in $83.7 \%$ of the MPS II patients, and patients underwent their first operation at a median age of 2.6 years. A median of 3 surgeries is performed in each MPS II patient [54]. The most common surgeries are tympanostomies/myringotomies, repair of inguinal hernias, adenoidectomy/tonsillectomy, and operations for carpal tunnel release. Valve replacement could be performed to manage cardiac valve manifestations that affect about half of the patients with MPS I and MPS II [107].

Rehabilitation therapy, including physical and occupational therapy, is required for patients with chronic physical disabilities and deformities to maintain physical function and activities of daily living. It provides a personalized treatment program according to each patient's symptoms and offers them a variety of treatment options. Approaches to enhance functional skills include gait training, static and dynamic balance, activities of daily living, and moving between positions. Physical therapy for children with MPS is to attain the developmental milestones and reach their full potential, and treatment is aimed at preventing future or present problems. Adults are more likely to have developed several complications. Hence, treatment in adults is carried out to maintain improvement, slow disease progression, and make the best use of preserved functions. 
TABLE 3: Management of unmanaged symptoms in MPS.

\begin{tabular}{|c|c|c|}
\hline Clinical symptoms & Monitoring ${ }^{\mathrm{a}, \mathrm{b}, \mathrm{c}, \mathrm{g}}$ & Treatment ${ }^{\mathrm{a}, \mathrm{b}, \mathrm{c}, \mathrm{d}, \mathrm{e}, \mathrm{f}, \mathrm{g}}$ \\
\hline Cardiac valve disease & Echocardiogram; cardiac MRI & Value replacement \\
\hline $\begin{array}{l}\text { Recurrent ear infections, hearing } \\
\text { loss }\end{array}$ & Otological and audiological examinations & Grommet; hearing aids \\
\hline Airway obstructions & Upper airway examination; sleep studies & $\begin{array}{c}\text { Respiratory physical therapy; positive airway pressure } \\
\text { ventilator }\end{array}$ \\
\hline Hernias & Clinical examination & Surgery \\
\hline \multicolumn{3}{|l|}{$\begin{array}{l}\text { Joint/Skeletal muscular } \\
\text { manifestations }\end{array}$} \\
\hline Joints contraction & 6-minute walk test; joint range of motion & Physical therapy; splints \\
\hline \multicolumn{3}{|l|}{ Kyphosis/scoliosis } \\
\hline \multicolumn{3}{|l|}{ Hip dysplasia } \\
\hline Genu valgum & Clinical examination & Surgery; physical/occupational therapy \\
\hline \multicolumn{3}{|l|}{ Abnormal gait } \\
\hline \multicolumn{3}{|l|}{ Ocular manifestations } \\
\hline Corneal clouding & & Contact lenses; corneal transplant \\
\hline Glaucoma & Clinical examination & Pressure-lowering eye drops \\
\hline Retinopathy & & N/A \\
\hline \multicolumn{3}{|l|}{ Neurological manifestations } \\
\hline Cognitive impairment & $\begin{array}{l}\text { Neurobehavioral assessment; cognitive } \\
\text { testing }\end{array}$ & $\begin{array}{c}\text { Stimulating environments; special schooling; speech } \\
\text { therapy }\end{array}$ \\
\hline Behavioral problems & Aim to rule out comorbid conditions & $\begin{array}{c}\text { Antipsychotics stimulants; mood stabilizer; behavioral } \\
\text { therapy }\end{array}$ \\
\hline Seizures & Brain MRI; EEG & Anticonvulsant therapy \\
\hline Hydrocephalus & Brain MRI & Ventriculoperitoneal shunting \\
\hline Carpal tunnel syndrome & $\begin{array}{l}\text { Nerve conduction studies; wrist } \\
\text { ultrasound }\end{array}$ & Decompression surgery \\
\hline Spinal cord compression & $\begin{array}{l}\text { Spine MRI; somatosensory evoked } \\
\text { potential }\end{array}$ & Decompression surgery, fixation (e.g., halo) \\
\hline
\end{tabular}

a Joseph Muenzer et al. (2008), "Mucopolysaccharidosis I: Management and Treatment Guidelines." b'Ana Maria Martins et al. (2009), "Guidelines for the Management of Mucopolysaccharidosis Type I." cMaurizio Scarpa et al. (2011), "MPS II European recommendations for the diagnosis and multidisciplinary management of rare disease." d Hernan Amartino(2015), "Hunter Syndrome (Mucopolysaccharidosis II) - The Signs and Symptoms a Neurologist Needs to Know." "Sun H. Peck et al. (2016), "Pathogenesis and Treatment of Spine Disease in the Mucopolysaccharidosis." fMaurizio Scarpaa et al. (2017), "Epilepsy in mucopolysaccharidosis disorders." "Shizuka Tomatsu et al. (2019), "Ophthalmological Findings in Mucopolysaccharidoses".

Previously approved medications can be used to alleviate symptoms. For example, standard agents are useful for cardiovascular manifestations. Hypertension could be treated using angiotensin-converting enzyme inhibitors, angiotensin receptor blockers, diuretics, and calcium channel blockers. Arrhythmias could be treated with antiarrhythmic drugs and anticoagulants [78].

2.4.1. Management of Musculoskeletal Manifestations. While ERT or HSCT improves the life expectancy in children with MPS, in most cases, their efficacy comes into question because still struggled a long time with performing daily activities and significantly reduced walking duration [108]. Skeletal manifestations persist as the most common symptoms in MPS I and MPS II. Pain and stiffness within the muscles or joints and the physical appearance can negatively impact the quality of life in children [109]. Rehabilitation therapy is required to prevent complications and delays the progression of the disease $[110,111]$. Patients should start at an early age to preserve functions for daily activity and slow symptom progression.
As many MPS children present with delayed development and/or neurological regression, gain motor skills at a slow rate, and begin to lose motor skills as the disease progresses [112, 113], the Bayley Scales of Infant Development II (BSID-II) is widely used for motor function evaluation in children with MPS. However, the BSID-II does not allow the determination of separate scores for gross and fine motor function [114], and children with MPS tend to get higher scores in fine motor skills than in gross motor skills, which inflate the standard scores of BSID-II. Therefore, the Peabody Developmental Motor scale is recommended for the assessment of motor skills in children with MPS [113]. Physical therapists and occupational therapists can provide proper exercise or treatment after a comprehensive examination. In physical therapy, family involvement determines in children's developmental outcomes [115].

Typical unmanaged musculoskeletal symptoms in children with MPS I and MPS II include spinal abnormalities, hip dysplasia, genu valgum (knock knees), joint abnormalities, and abnormal gait. Kyphosis/scoliosis is a common 
spinal abnormality that results in pain, disability, cardiorespiratory complications, and even death [116]. Management of kyphosis/scoliosis involves physical therapy, usually applied for curves between $18^{\circ}$ and $45^{\circ}$ to straighten the spine as much as possible and avoid cardiopulmonary and neurological problems [116-118]. Although it is hard to prevent the progression of kyphoscoliosis, physical therapy can delay the postural collapse biomechanically that causes secondary functional impairment (such as restrictive pulmonary disease and reduced cardiopulmonary performance) and reduce pain $[116,119]$.

Hip dysplasia is characterized by an abnormality of the articular and periarticular structures and is defined by the instability of the hip, capsular laxity, or abnormal acetabulum. Orthopedic/physical therapy is important to correct hip position and articular angle and prevent further deterioration of the articular/periarticular structures. Diagnosis of hip dysplasia is established by reduced mobility movement, frontal pelvic asymmetry, higher contractures in the lumbar paravertebral muscles in the part of the hip with dysplasia, and difficulties in maintaining the prone position for more than 10 seconds. Physical therapy such as Swedish massage, posturing, and passive and active mobilization could be applied for regaining hip mobility/full range of motion, strengthening the hypotonic muscles, rebalancing the pelvic asymmetry, and increasing the passive and active stability of hip joints [120].

If joint stiffness or contracture is present, manual and active joint exercises could be applied to maintain or enhance range of motion (ROM). Subluxation is caused by the unalignment of the wing bone and clavicle and weakening or shortening of shoulder muscles, which can be managed by muscle strengthening or electrical stimulation. Joint ROM exercises may offer some benefits, so patients should start at an early age to preserve joint function and slow symptom progression. Repeated joint stretching during daily activities is beneficial to maintain joint motion. For example, stretching via long sitting or wedge standing while watching TV can helpful in addressing the knee ROM. Patients are advised to wear splints throughout the night while sleeping to maintain or regain the range of motion [121].

Genu valgum refers to abnormal knee alignment states in the frontal plane that cause problems in the overall alignment of the lower extremities and the knee joints and lead to osteoarthritis or knee deformities, increasing the risk of falls due to reduced postural stability $[122,123]$. Genu valgum may involve the hip and the subtalar joint, as well as the patellofemoral joint, and treatment approaches should be applied accordingly. Adjustment of the joint and muscle alignment can be considered in some cases. Supportive devices such as orthotic footwear and walking aids can assist with daily living activities.

Abnormal gait is another problem encountered in children with MPS. Several studies have reported that strengthening exercise of lower extremities, balance exercise, and repetitive locomotor training may improve gait function [124-126]. When a child has difficulty walking/struggles with walking, the use of a standing frame or tilt-table can prevent osteoporosis or improve joint range of motion [127].
Hydrotherapy has been used for musculoskeletal and neuromuscular rehabilitation for more than 100 years, with improved motor performance in children with muscular dystrophy, cystic fibrosis, spina bifida, Rett syndrome, cerebral palsy, multiple sclerosis, and Parkinson's disease [128-131]. It is an effective yet enjoyable therapy for children with motor disabilities that can be administered to children with MPS I and MPS II, who are unable to perform certain activities on land $[66,132]$. Hydrotherapy reduces excessive joint loading, enhances strengthening, and provides assistance to children with decreased postural control and muscle weakness $[128,131]$. Buoyancy offers support to the joints and counteracts the gravitational force, which may facilitate postural control. Hydrostatic pressure provides different sensory feedback than land-based exercise, thus influencing balance competence and postural control [133]. Water resistance facilitates various forms of exercise, providing receptive resistance to muscle strengthening [131]. The warm temperature $\left(33^{\circ} \mathrm{C}-35^{\circ} \mathrm{C}\right)$ reduces muscle spindle activity, promotes muscle relaxation, and reduces spasticity, which leads to an increased ROM in the joints and offers improved postural alignment [134]. It also provides the opportunity to experience, learn, and enjoy new movement skills, which result in increased functional skills and mobility, and builds self-confidence.

Surgical interventions for musculoskeletal manifestations include arthroscopy, hip or knee replacement, and correction of the lower limb axis. These orthopedic treatments can help address the psychosocial aspects of the disease, such as loss of mobility and independence $[58,70,78]$. Surgical intervention should be considered with caution, as the short neck, immobile jaw, and pathological changes in the airway found in patients with MPS make general anesthesia a challenging and high-risk procedure $[78,135]$.

2.4.2. Management of Airway Abnormalities. Typical features of MPS include upper and lower airway obstruction and restrictive pulmonary disease, which can lead to chronic rhinosinusitis, recurrent upper and lower respiratory tract infections, and obstructive sleep apnea [136]. Upper airway obstruction may occur due to the deposition of GAGs in the soft tissues of the throat and trachea [135]. Patients with MPS should receive regular assessment for airway obstruction, and sleep studies are required in patients with sleep apnea [37, 135, 137]. Adenotonsillectomy, surgery of the nasal or shell, tracheostomy, and laser surgery of tracheal lesions are common surgical procedures for airway disorders in MPS patients [70]. The treatment of sleep apnea includes nocturnal supplemental oxygen. Although tonsillectomy and adenoidectomy may be performed when these are enlarged, temporary or partial improvement is observed due to the progressive disease character [54]. Respiratory support is useful for patients with manifestations of airway disease. Continuous positive airway pressure can be adopted to improve airway potency during sleep. It leads to significant improvements in sleep quality and a reduction in fatigue or headache complaints the following day $[78,135]$.

Respiratory physical therapy can be applied to patients with MPS to improve pulmonary ventilation and respiratory 
biomechanics. Upper airway obstruction, thoracic deformity, muscular shortening, protruding abdomen, and bronchoaspiration caused by dysphagia may lead to a reduction in abdominal thorax expansion and mobility, absence of productive cough, recurrent infections, and hypersecretion in MPS patients [108]. Pulmonary rehabilitation is a key component of managing obstructive airway symptoms, which involves exercise training, education, and self-management interventions [138]. Since patients exhibit reduction of thoracic volume and restriction of the diaphragmatic movement, increasing the flexibility of thoracic cage and strengthening the diaphragm muscle are needed [139]. Considering diaphragm is the main breathing muscle and patients suffer diaphragmatic weakness from spinal cord compression, it is important to perform diaphragmatic breathing and strengthen diaphragmatic muscles [140, 141]. Weakness of expiratory muscles and absence of/reduced productive cough lead to reduced airway clearance. Treatment options to assist airway clearance may include postural drainage, manual cough assistance, percussion, and vibration (chest clapping/shaking), a forced expiratory manoeuvre such as huffing, and an active cycle of breathing techniques [142]. Positive expiratory pressure (PEP) devices such as expiratory muscle strength training, TheraPEP, flutter, and acapella, highfrequency chest wall oscillation, and cough assist machine may be used for expiratory muscles strengthening and secretion clearance assistance. Blowing up a balloon or blowing out candles could be considered as a play therapy for MPS children.

2.4.3. Management of Ocular Manifestations. Ocular involvement in MPS I generally consists of corneal clouding, retinopathy, glaucoma, and optic nerve abnormalities. Although MPS II is associated with similar ocular manifestations, corneal clouding resulting from the building up of GAGs (most likely HS) in stromal keratocytes is rarely encountered [12]. HSCT is reported to stabilize or improve corneal opacification, visual acuity, and optic nerve swelling [143], but is ineffective in preventing retinal degeneration [144]. ERT associates with stabilization of corneal clouding; however, the effects on visual acuity, optic nerve edema, or atrophy are inconclusive $[12,49]$. Ocular evaluation and management should be comprehensive, and patients should receive monitoring every 6 to 12 months during preschool age and then every year until they reach the age of 18 [144]. Visual field tests are difficult to perform as most patients with MPS are very young with developmental delays [12].

The treatment of ocular complications in MPS does not differ substantially from approaches used for otherwise healthy individuals. Corneal transplants could be used to manage severe corneal clouding and restore corneal transparency [48]. However, reopacification occurs as early as 1 year after surgery due to GAG deposition in the graft without systemic treatment. Moreover, the graft visual acuity is often limited due to the secondary compromise of the retina and optic nerve [12]. Both penetrating keratoplasty (PK) and deep anterior lamellar keratoplasty (DALK) can be applied to patients. However, DALK is recommended over PK due to decreased risk of rejection [48]. Recently, a limbal stem cell transplant combined with keratoplasty is recommended to restore healthy limbal epithelial host cells and delay or prevent the recurrence of corneal opacification [12, 49, 145].

Management of glaucoma is difficult due to the limited effectiveness of antiglaucoma therapy and the progressive disease characteristics [12]. GAG accumulation in the trabecular meshwork and aqueous outflow pathways can lead to glaucomatous changes in the optic nerve, seen in other forms of open-angle glaucoma pathophysiology. GAGs depositions in the peripheral cornea, other anterior chamber structures, and cystic changes in the ciliary body may lead to closedangle glaucoma. Notably, measured elevated intraocular pressure (IOP) may be inaccurate for MPS patients [48]. Patients may have falsely elevated IOP due to the increased corneal rigidity. For a thorough evaluation of glaucoma, advanced technologies such as ultrasound biomicroscopy and anterior segment optical coherence tomography that can visualize the anatomy behind the potentially hazed cornea could be used for diagnosis and monitoring. Patients diagnosed with glaucoma may benefit from the use of IOPlowering eye drops.

Management of retinopathy is challenging, as no positive effects have been observed with ERT or HSCT. Patients with MPS may exhibit retinopathy with pigmentary retinal degeneration and associated electroretinogram changes due to GAG deposition in the retinal pigment epithelial cells, resulting in photoreceptor loss. For corneal clouding or photophobia in MPS patients, the diagnosis of retinopathy requires a comprehensive examination with fundus photography or echography for the assessment of the optic nerve and retinal pathologies [48]. There is no treatment available for optic nerve involvement associated with retinal degeneration. However, as previously mentioned, the approval of Luxturna $^{\mathrm{TM}}$ as gene therapy for RPE65 mutation-associated retinal dystrophy brings hope to MPS patients. Considering the sustained expression and action of $\beta$-glucuronidase in MPS VII canine retinal pigment epithelium transduced with AAV virus vector containing $\beta$-glucuronidase cDNA in vitro [146], successful management of retinal pathology in MPS will be realized in the future.

2.4.4. Management of Neurological Manifestations. Nerve conduction studies should be performed every 1 to 2 years, from 4 to 5 years of age, to monitor peripheral nerve function and the development of carpal tunnel syndrome [59, 66, 144]. Carpal tunnel syndrome is a rare finding in healthy children but frequently reported in children with MPS I and MPS II [147, 148]. Patients have distorted bony architecture in the distal wrist, including distal radio-ulnar dislocation, small irregular carpal bones, and short tubular metacarpals with decompression of the median nerve. All these physiological abnormalities lead to loss of sensation or abnormal nerve conduction [149]. Decompression surgery should be performed for patients who suffer from carpal tunnel syndrome with loss of hand sensation or function [59]. Spinal cord compression, which results in cervical myelopathy, occurs due to cervical stenosis, thoracolumbar kyphosis/scoliosis, and lumbar canal stenosis [150]. It should be addressed by depression surgery before irreversible cord 


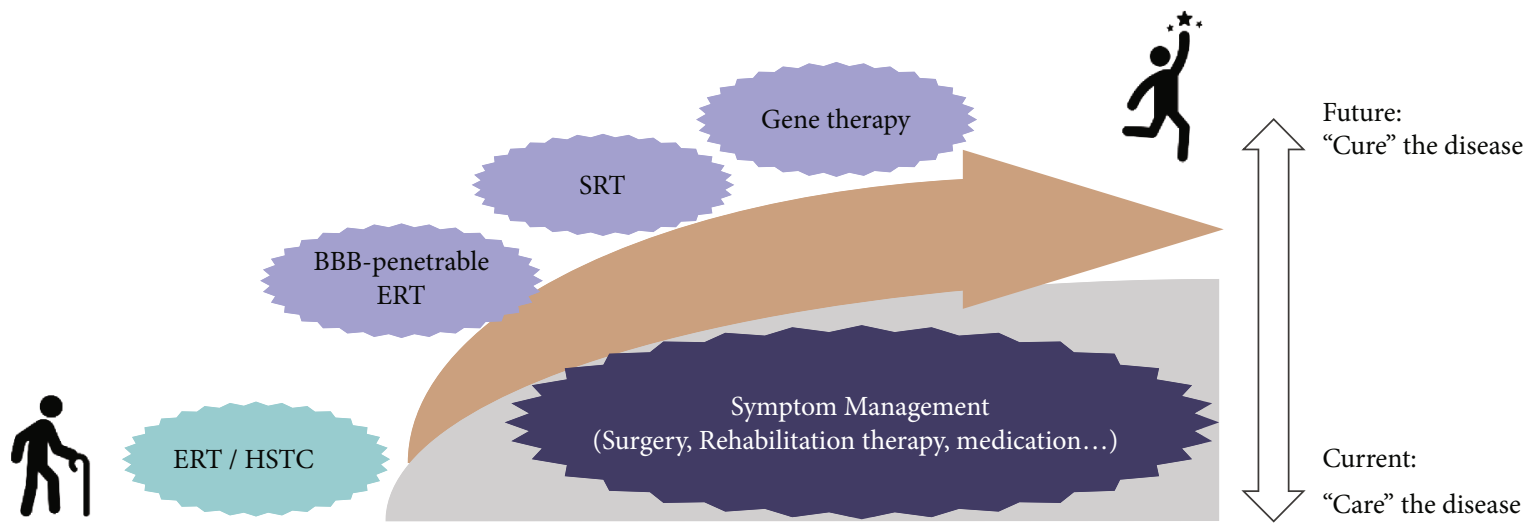

FIgURE 1: Therapeutic options and management strategy of MPS I and II.

damage occurs $[137,151,152]$. It is important to detect spinal cord compression as early as possible before an irreversible loss of motor function or sensation in all limbs occurs [59]. After decompression surgery, several methods have been introduced, namely, in situ fusion using a halo-vest, cables or wires, transarticular screws, or laminar screws. A halovest could stabilize the head and neck during and after the surgery in children with MPS, whereas Mayfield fixators are used for adults [150]. A collar can be used by MPS children with mild symptoms immediately after surgery. Children can switch to a neck restraint or collar after 3 to 6 months of wearing halo-neck braces.

Previously approved standard medications can be used to alleviate symptoms of pain, seizures, sleep disorders, and psychiatric problems. Anticonvulsant therapy can reduce the frequency of seizures and may improve sleep, cognitive, and behavioral symptoms $[55,137,153]$. Although antipsychotic agents and attention stimulants may improve behavioral disorders associated with MPS II, the prescription should be used with caution due to the limited number of reports on the efficacy of the reagent [59]. Given the cognitive impairment and developmental delay in severe types of MPS I and MPS II, it is important to provide MPS children with a stimulating learning environment to achieve learning and normal developmental milestones as early as possible before deterioration occurs in the later stage. Special schooling or speech therapy is recommended for patients with cognitive impairments or behavioral problems [59].

\section{Conclusions}

MPS I and MPS II show a wide spectrum of clinical manifestations and disease severity. A comparison of the natural history illustrates that the onset of both somatic and central nervous system manifestations occur earlier in severe type of MPS I than in MPS II. Although HSCT and ERT have advantages in alleviating soft tissue-related concerns and offer improvements in walking distance, forced vital capacity, respiratory symptoms, cardiovascular symptoms, and hepatomegaly, these therapeutic modalities are ineffective for brain-related dysfunction, bone deformity, and optic nerve disorders.
Many pharmaceutical companies are developing BBBpenetrable ERT to control CNS manifestations currently uncontrolled with ERT and overcome the limitations of ERT and HSCT. The development strategy is to conjugate the BBB-targeting antibody or sequence to approved ERT drugs and enable drug delivery into the brain. As this approach is in the late stages of clinical trials, it is expected that BBB-penetrable ERT will be commercialized within next few years. Secondly, orally available SRT drugs would take some more time for commercialization. SRT is expected to address the shortcomings of ERT, such as its limited effect due to distribution problem, and provide solutions for the unmanaged manifestations of neurological, musculoskeletal, and ophthalmological symptoms. Lastly, gene therapy exhibits the advantage of producing life-long effects with one or two administrations. It is an ideal strategy to "cure" the disease rather than support by "care." Although gene therapy has shown promising results in preclinical and clinical studies, it requires some more time to show benefits in MPS patients. Gene therapies are thoroughly studied in early clinical stages of development and need to overcome safety issue such as genotoxicity and long-term safety. Some clinical studies reveal that the delivery of genes directly into the brain provides better control of neurological symptoms than intravenous systemic administration.

In these circumstances, it is important to manage the disease with regular follow-ups and supportive/palliative therapy to relieve the symptoms (Figure 1). Surgical interventions, physical therapy, hydrotherapy, and symptomatic medications could be considered for patients with MPS I and MPS II. Musculoskeletal manifestations can be managed by orthopedic surgery, including arthroscopy, hip or knee replacement, and correction of the lower limb axis, even before disease diagnosis. Physical and occupational therapy provide personalized exercise and treatment for patients (according to their status) to prevent or improve musculoskeletal abnormalities. Hydrotherapy, which is widely used for musculoskeletal and neuromuscular rehabilitation and demonstrates improved motor performance in many diseases, could be applied to MPS patients as play therapy. To manage airway abnormalities, respiratory physical therapy that is aimed at improving the pulmonary ventilation and respiratory biomechanics may benefit patients. 
Continuous positive airway pressure could be applied for patients with sleep problems. Treatment of ocular complications in MPS patients does not differ substantially from approaches used for otherwise healthy individuals. With the advent of gene therapy, successful management of retinal pathology in MPS I and MPS II will be realized in the near future. For carpal tunnel syndrome and spinal cord compression, decompression surgery should be performed as early as possible before an irreversible loss of motor function or sensation occurs. Standard medications can be used to alleviate neurological symptoms, such as pain, seizures, sleep disorders, and psychiatric problems. Providing a stimulating environment for children living with MPS and allowing them to achieve learning and normal developmental milestones are crucial.

In summary, health care providers should consider the unique disease characteristics and manifestations of each patient carefully before prescribing any treatment modalities. In addition, they can suggest appropriate supportive and palliative therapies that benefit their patients most.

\section{Data Availability}

No data were used to support this study.

\section{Conflicts of Interest}

The authors declare that there is no conflict of interest regarding the publication of this paper.

\section{Acknowledgments}

The authors are grateful to the reviewers who provided useful feedback during the peer review process.

\section{Supplementary Materials}

Figure S1: degradation process of GAG chains and enzyme malfunction in each step. Table S1: deficient enzymes, accumulated substrate, and incidence of each MPS type. (Supplementary Materials)

\section{References}

[1] J. J. Castellot Jr., R. L. Hoover, P. A. Harper, and M. J. Karnovsky, "Heparin and glomerular epithelial cell-secreted heparin-like species inhibit mesangial-cell proliferation," The American Journal of Pathology, vol. 120, no. 3, pp. 427435, 1985.

[2] S. Yamada, K. Sugahara, and S. Özbek, "Evolution of glycosaminoglycans: comparative biochemical study," Communicative \& Integrative Biology, vol. 4, pp. 150-158, 2014.

[3] N. Afratis, C. Gialeli, D. Nikitovic et al., "Glycosaminoglycans: key players in cancer cell biology and treatment," The FEBS Journal, vol. 279, no. 7, pp. 1177-1197, 2012.

[4] N. S. Gandhi and R. L. Mancera, "The structure of glycosaminoglycans and their interactions with proteins," Chemical Biology \& Drug Design, vol. 72, no. 6, pp. 455-482, 2008.

[5] K. Shimada and B. L. Fanburg, "Involvement of cell surface heparan sulfate in the binding of lipoprotein lipase to cul- tured endothelial cells," Japanese Circulation Journal, vol. 46, pp. 995-1002, 1982.

[6] M. Guilarte, A. Sala-Cunill, O. Luengo, M. Labrador-Horrillo, and V. Cardona, "The mast cell, contact, and coagulation system connection in anaphylaxis," Frontiers in Immunology, vol. 8, 2017.

[7] V. Valayannopoulos and F. A. Wijburg, "Therapy for the mucopolysaccharidoses," Rheumatology, vol. 50, Supplement 5, pp. v49-v59, 2011.

[8] C. Cingi, "Otolaryngological findings in mucopolysaccharidosis," Journal of Medical Updates, vol. 4, no. 3, pp. 122129, 2014.

[9] M. Filocamo, R. Tomanin, F. Bertola, and A. Morrone, "Biochemical and molecular analysis in mucopolysaccharidoses: what a paediatrician must know," Italian Journal of Pediatrics, vol. 44, no. S2, p. 129, 2018.

[10] S. A. Khan, H. Peracha, D. Ballhausen et al., "HHS public access," Molecular Genetics and Metabolism, vol. 121, pp. 227-240, 2018.

[11] J. L. Ashworth, S. Biswas, E. Wraith, and I. C. Lloyd, "Mucopolysaccharidoses and the eye," Survey of Ophthalmology, vol. 51, no. 1, pp. 1-17, 2006.

[12] C. R. Fenzl, K. Teramoto, and M. Moshirfar, "Ocular manifestations and management recommendations of lysosomal storage disorders I: mucopolysaccharidoses," Clinical Ophthalmology, vol. 9, pp. 1633-1644, 2015.

[13] J. Muenzer, "Overview of the mucopolysaccharidoses," Rheumatology, vol. 50, Supplement 5, pp. v4-12, 2011.

[14] B. J. H. M. Poorthuis, R. A. Wevers, W. J. Kleijer et al., "The frequency of lysosomal storage diseases in the Netherlands," Human Genetics, vol. 105, no. 1, p. 151, 1999.

[15] P. J. Meikle, J. J. Hopwood, A. E. Clague, and W. F. Carey, "Prevalence of lysosomal storage disorders," Journal of the American Medical Association, vol. 281, no. 3, pp. 249-254, 1999.

[16] J. Nelson, "Incidence of the mucopolysaccharidoses in Northern Ireland," Human Genetics, vol. 101, no. 3, pp. 355-358, 1997.

[17] J. Nelson, J. Crowhurst, B. Carey, and L. Greed, "Incidence of the mucopolysaccharidoses in Western Australia," American Journal of Medical Genetics, vol. 123A, no. 3, pp. 310-313, 2003.

[18] R. B. Lowry and D. H. G. Renwick, "Relative frequency of the hurler and hunter syndromes," The New England Journal of Medicine, vol. 284, no. 4, pp. 221-222, 1971.

[19] D. A. Applegarth, J. R. Toone, and R. Brian Lowry, "Incidence of inborn errors of metabolism in British Columbia, 19691996," Pediatrics, vol. 105, p. 109, 2000.

[20] B. Triggs-Raine, T. J. Salo, H. Zhang, B. A. Wicklow, and M. R. Natowicz, "Mutations in HYAL1, a member of a tandemly distributed multigene family encoding disparate hyaluronidase activities, cause a newly described lysosomal disorder, mucopolysaccharidosis IX," Proceedings of the National Academy of Sciences of the United States of America, vol. 96, no. 11, pp. 6296-6300, 1999.

[21] L. Imundo, C. A. LeDuc, S. Guha et al., "A complete deficiency of Hyaluronoglucosaminidase 1 (HYAL1) presenting as familial juvenile idiopathic arthritis," Journal of Inherited Metabolic Disease, vol. 34, no. 5, pp. 1013-1022, 2011.

[22] J. Zhou, J. Lin, W. T. Leung, and L. Wang, "A basic understanding of mucopolysaccharidosis: incidence, clinical 
features, diagnosis, and management," Intractable \& Rare Diseases Research, vol. 9, no. 1, pp. 1-9, 2020.

[23] F. Baehner, C. Schmiedeskamp, F. Krummenauer et al., "Cumulative incidence rates of the mucopolysaccharidoses in Germany," Journal of Inherited Metabolic Disease, vol. 28, no. 6, pp. 1011-1017, 2005.

[24] S. Y. Cho, Y. B. Sohn, and D. K. Jin, “An overview of Korean patients with mucopolysaccharidosis and collaboration through the Asia Pacific MPS Network," Intractable \& Rare Diseases Research, vol. 3, no. 3, pp. 79-86, 2014.

[25] G. Malm, A. M. Lund, J. E. Månsson, and A. Heiberg, "Mucopolysaccharidoses in the Scandinavian countries: incidence and prevalence," Acta Paediatrica, vol. 97, no. 11, pp. 15771581, 2008.

[26] H. Moammar, G. Cheriyan, R. Mathew, and N. Al-Sannaa, "Incidence and patterns of inborn errors of metabolism in the eastern province of Saudi Arabia, 1983-2008," Annals of Saudi Medicine, vol. 30, no. 4, pp. 271-277, 2010.

[27] S. A. Khan, H. Peracha, D. Ballhausen et al., "Epidemiology of mucopolysaccharidoses," Molecular Genetics and Metabolism, vol. 121, no. 3, pp. 227-240, 2017.

[28] R. Manara, E. Priante, M. Grimaldi et al., "Brain and spine MRI features of Hunter disease: frequency, natural evolution and response to therapy," Journal of Inherited Metabolic Disease, vol. 34, no. 3, pp. 763-780, 2011.

[29] I. Nestrasil and L. Vedolin, "Quantitative neuroimaging in mucopolysaccharidoses clinical trials," Molecular Genetics and Metabolism, vol. 122, pp. 17-24, 2017.

[30] M. C. Bax and G. A. Colville, "Behaviour in mucopolysaccharide disorders," Archives of Disease in Childhood, vol. 73, no. 1, pp. 77-81, 1995.

[31] G. Węgrzyn, J. Jakóbkiewicz-Banecka, M. Narajczyk et al., "Why are behaviors of children suffering from various neuronopathic types of mucopolysaccharidoses different?," Medical Hypotheses, vol. 75, no. 6, pp. 605-609, 2010.

[32] E. G. Shapiro, L. A. Lockman, M. Balthazor, and W. Krivit, "Neuropsychological outcomes of several storage diseases with and without bone marrow transplantation," Journal of Inherited Metabolic Disease, vol. 18, no. 4, pp. 413429, 1995.

[33] S. Tomatsu, K. Okamura, H. Maeda et al., "Keratan sulphate levels in mucopolysaccharidoses and mucolipidoses," Journal of Inherited Metabolic Disease, vol. 28, no. 2, pp. 187-202, 2005.

[34] M. H. Gelb, F. Turecek, C. R. Scott, and N. A. Chamoles, "Direct multiplex assay of enzymes in dried blood spots by tandem mass spectrometry for the newborn screening of lysosomal storage disorders," Journal of Inherited Metabolic Disease, vol. 29, no. 2-3, pp. 397-404, 2006.

[35] P. J. Meikle, D. J. Grasby, C. J. Dean et al., "Newborn screening for lysosomal storage disorders," Molecular Genetics and Metabolism, vol. 88, no. 4, pp. 307-314, 2006.

[36] S. Tomatsu, T. Fujii, M. Fukushi et al., "Newborn screening and diagnosis of mucopolysaccharidoses," Molecular Genetics and Metabolism, vol. 110, no. 1-2, pp. 42-53, 2013.

[37] L. A. Clarke, A. M. Atherton, B. K. Burton et al., "Mucopolysaccharidosis type I newborn screening: best practices for diagnosis and management," The Journal of Pediatrics, vol. 182, pp. 363-370, 2017.

[38] P. V. Hopkins, C. Campbell, T. Klug, S. Rogers, J. RaburnMiller, and J. Kiesling, "Lysosomal storage disorder screening implementation: findings from the first six months of full population pilot testing in Missouri," The Journal of Pediatrics, vol. 166, no. 1, pp. 172-177, 2015.

[39] C. R. Scott, S. Elliott, N. Buroker et al., "Identification of infants at risk for developing Fabry, Pompe, or mucopolysaccharidosis-I from newborn blood spots by tandem mass spectrometry," The Journal of Pediatrics, vol. 163, no. 2, pp. 498-503, 2013.

[40] S.-P. Lin, H.-Y. Lin, T.-J. Wang et al., "A pilot newborn screening program for Mucopolysaccharidosis type i in Taiwan," Orphanet Journal of Rare Diseases, vol. 8, no. 1, p. 147, 2013.

[41] S. Paciotti, E. Persichetti, S. Pagliardini et al., "First pilot newborn screening for four lysosomal storage diseases in an Italian region: identification and analysis of a putative causative mutation in the GBA gene," Clinica Chimica Acta, vol. 413, no. 23-24, pp. 1827-1831, 2012.

[42] J. B. Holt, M. D. Poe, and M. L. Escolar, "Natural progression of neurological disease in mucopolysaccharidosis type II," Pediatrics, vol. 127, no. 5, pp. e1258-e1265, 2011.

[43] J. E. Wraith and S. Jones, "Mucopolysaccharidosis type I," Pediatric Endocrinology Reviews, Supplement 1, pp. 102106, 2014.

[44] C. Meaney, G. Greenland, V. Adams et al., "Mutational analysis of 85 mucopolysaccharidosis type I families: frequency of known mutations, identification of 17 novel mutations and in vitro expression of missense mutations," Human Genetics, vol. 109, no. 5, pp. 503-511, 2001.

[45] E. G. Shapiro, S. A. Jones, and M. L. Escolar, "Developmental and behavioral aspects of mucopolysaccharidoses with brain manifestations - neurological signs and symptoms," Molecular Genetics and Metabolism, vol. 122, pp. 1-7, 2017.

[46] M. Beck, P. Arn, R. Giugliani et al., "The natural history of MPS I: global perspectives from the MPS I Registry," Genetics in Medicine, vol. 16, no. 10, pp. 759-765, 2014.

[47] M. Scarpa, C. M. Lourenço, and H. Amartino, "Epilepsy in mucopolysaccharidosis disorders," Molecular Genetics and Metabolism, vol. 122, pp. 55-61, 2017.

[48] S. Tomatsu, S. Pitz, and U. Hampel, "Ophthalmological findings in mucopolysaccharidoses," Journal of Clinical Medicine, vol. 8, no. 9, p. 1467, 2019.

[49] A. Ganesh, Z. Bruwer, and K. Al-Thihli, "An update on ocular involvement in mucopolysaccharidoses," Current Opinion in Ophthalmology, vol. 24, no. 5, pp. 379-388, 2013.

[50] S. Ferrari, D. Ponzin, J. L. Ashworth et al., "Diagnosis and management of ophthalmological features in patients with mucopolysaccharidosis," The British Journal of Ophthalmology, vol. 95, no. 5, pp. 613-619, 2011.

[51] G.-A. Kuiper, E. J. Langereis, S. Breyer et al., "Treatment of thoracolumbar kyphosis in patients with mucopolysaccharidosis type I: results of an international consensus procedure," Orphanet Journal of Rare Diseases, vol. 14, no. 1, p. 17, 2019.

[52] T. Kato, Z. Kato, I. Kuratsubo et al., "Mutational and structural analysis of Japanese patients with mucopolysaccharidosis type II," Journal of Human Genetics, vol. 50, no. 8, pp. 395-402, 2005.

[53] J. E. Wraith, M. Beck, R. Giugliani et al., "Initial report from the hunter outcome survey," Genetics in Medicine, vol. 10, no. 7, pp. 508-516, 2008.

[54] N. J. Mendelsohn, P. Harmatz, O. Bodamer et al., "Importance of surgical history in diagnosing 
mucopolysaccharidosis type II (Hunter syndrome): data from the Hunter Outcome Survey," Genetics in Medicine, vol. 12, no. 12, pp. 816-822, 2010.

[55] J. E. Wraith, M. Scarpa, M. Beck et al., "Mucopolysaccharidosis type II (Hunter syndrome): a clinical review and recommendations for treatment in the era of enzyme replacement therapy," European Journal of Pediatrics, vol. 167, no. 3, pp. 267-277, 2008.

[56] J. Holt, M. D. Poe, and M. L. Escolar, "Early clinical markers of central nervous system involvement in mucopolysaccharidosis type II," The Journal of Pediatrics, vol. 159, no. 2, pp. 320-326.e2, 2011.

[57] R. Giugliani, M. L. S. Villarreal, C. A. A. Valdez et al., "Guidelines for diagnosis and treatment of Hunter syndrome for clinicians in Latin America," Genetics and Molecular Biology, vol. 37, no. 2, pp. 315-329, 2014.

[58] B. Link, L. L. de Camargo Pinto, R. Giugliani et al., "Orthopedic manifestations in patients with muco-polysaccharidosis type II (Hunter syndrome) enrolled in the Hunter Outcome Survey," Orthopedic Reviews, vol. 2, no. 2, p. 16, 2010.

[59] H. Amartino, "Hunter syndrome (Mucopolysaccharidosis ii) -the signs and symptoms a neurologist needs to know," European Neurological Review, vol. 10, no. 1, pp. 90-94, 2015.

[60] R. Cimaz and F. La Torre, "Mucopolysaccharidoses," Current Rheumatology Reports, vol. 16, no. 1, p. 389, 2014.

[61] K. Sawamoto, M. Stapleton, C. J. Alméciga-Díaz et al., “Therapeutic options for mucopolysaccharidoses: current and emerging treatments," Drugs, vol. 79, no. 10, pp. 11031134, 2019.

[62] A. Fraldi, M. Serafini, N. C. Sorrentino, B. Gentner, A. Aiuti, and M. E. Bernardo, "Gene therapy for mucopolysaccharidoses: in vivo and ex vivo approaches," Italian Journal of Pediatrics, vol. 44, Supplement 2, p. 130, 2018.

[63] C. Peters, M. Balthazor, E. G. Shapiro et al., "Outcome of unrelated donor bone marrow transplantation in 40 children with Hurler syndrome," Blood, vol. 87, no. 11, pp. 4894-4902, 1996.

[64] C. Peters, E. G. Shapiro, J. Anderson et al., "Hurler syndrome: II. Outcome of HLA-genotypically identical sibling and HLA-haploidentical related donor bone marrow transplantation in fifty-four children," Blood, vol. 91, no. 7, pp. 26012608, 1998.

[65] J. R. Hobbs, A. J. Barrett, D. Chambers et al., "Reversal of clinical features of Hurler's disease and biochemical improvement after treatment by bone-marrow transplantation," The Lancet, vol. 318, no. 8249, pp. 709-712, 1981.

[66] J. Muenzer, J. E. Wraith, and L. A. Clarke, "Mucopolysaccharidosis I: management and treatment guidelines," Pediatrics, vol. 123, no. 1, pp. 19-29, 2009.

[67] G. Souillet, N. Guffon, I. Maire et al., "Outcome of 27 patients with Hurler's syndrome transplanted from either related or unrelated haematopoietic stem cell sources," Bone Marrow Transplantation, vol. 31, no. 12, pp. 1105-1117, 2003.

[68] E. Herskhovitz, E. Young, J. Rainer et al., "Bone marrow transplantation for Maroteaux-Lamy syndrome (MPS VI): long-term follow-up," Journal of Inherited Metabolic Disease, vol. 22, no. 1, pp. 50-62, 1999.

[69] Y. Yamada, K. Kato, K. Sukegawa et al., "Treatment of MPS VII (Sly disease) by allogeneic BMT in a female with homozygous A619V mutation," Bone Marrow Transplantation, vol. 21, no. 6, pp. 629-634, 1998.
[70] A. M. Martins, A. P. Dualibi, D. Norato et al., "Guidelines for the management of mucopolysaccharidosis type I," The Journal of Pediatrics, vol. 155, 2009.

[71] N. J. Rodgers, A. M. Kaizer, W. P. Miller, K. D. Rudser, P. J. Orchard, and E. A. Braunlin, "Mortality after hematopoietic stem cell transplantation for severe mucopolysaccharidosis type I: the 30-year University of Minnesota experience," Journal of Inherited Metabolic Disease, vol. 40, no. 2, pp. 271-280, 2017.

[72] S. H. Lum, K. M. Stepien, A. Ghosh et al., "Long term survival and cardiopulmonary outcome in children with Hurler syndrome after haematopoietic stem cell transplantation," Journal of Inherited Metabolic Disease, vol. 40, pp. 455-460, 2017.

[73] V. K. Prasad and J. Kurtzberg, "Transplant outcomes in mucopolysaccharidoses," Seminars in Hematology, vol. 47, no. 1, pp. 59-69, 2010.

[74] M. Aldenhoven, S. A. Jones, D. Bonney et al., "Hematopoietic cell transplantation for mucopolysaccharidosis patients is safe and effective: results after implementation of international guidelines," Biology of Blood and Marrow Transplantation, vol. 21, no. 6, pp. 1106-1109, 2015.

[75] M. Aldenhoven, R. F. Wynn, P. J. Orchard et al., "Long-term outcome of Hurler syndrome patients after hematopoietic cell transplantation: an international multicenter study," Blood, vol. 125, no. 13, pp. 2164-2172, 2015.

[76] S. Tomatsu, I. Azario, K. Sawamoto, A. S. Pievani, A. Biondi, and M. Serafini, "Neonatal cellular and gene therapies for mucopolysaccharidoses: the earlier the better?," Journal of Inherited Metabolic Disease, vol. 39, no. 2, pp. 189-202, 2016.

[77] M. H. de Ru, J. J. Boelens, A. M. Das et al., "Enzyme replacement therapy and/or hematopoietic stem cell transplantation at diagnosis in patients with mucopolysaccharidosis type I: results of a European consensus procedure," Orphanet Journal of Rare Diseases, vol. 6, pp. 1-9, 2011.

[78] M. Scarpa, Z. Almássy, M. Beck et al., "Mucopolysaccharidosis type II: European recommendations for the diagnosis and multidisciplinary management of a rare disease," Orphanet Journal of Rare Diseases, vol. 6, pp. 1-18, 2011.

[79] H. Noh and J. I. Lee, "Current and potential therapeutic strategies for mucopolysaccharidoses," Journal of Clinical Pharmacy and Therapeutics, vol. 39, no. 3, pp. 215-224, 2014.

[80] E. Jameson, S. Jones, and T. Remmington, "Enzyme replacement therapy with laronidase (Aldurazyme ${ }^{\circledR}$ ) for treating mucopolysaccharidosis type I," Cochrane Database of Systematic Reviews, vol. 2019, 2019.

[81] D. Concolino, F. Deodato, and R. Parini, "Enzyme replacement therapy: efficacy and limitations," Italian Journal of Pediatrics, vol. 44, Supplement 2, p. 120, 2018.

[82] L. H. Ngu, W. Ong Peitee, H. Y. Leong, and H. B. Chew, "Case report of treatment experience with idursulfase beta (Hunterase) in an adolescent patient with MPS II," Molecular Genetics and Metabolism Reports, vol. 12, pp. 28-32, 2017.

[83] J. Muenzer, "Early initiation of enzyme replacement therapy for the mucopolysaccharidoses," Molecular Genetics and Metabolism, vol. 111, pp. 63-72, 2014.

[84] B. K. Burton, V. Jego, J. Mikl, and S. A. Jones, "Survival in idursulfase-treated and untreated patients with mucopolysaccharidosis type II: data from the Hunter Outcome Survey (HOS)," Journal of Inherited Metabolic Disease, vol. 40, no. 6, pp. 867-874, 2017.

[85] B. W. Bigger, M. Saif, and G. E. Linthorst, "The role of antibodies in enzyme treatments and therapeutic strategies," Best 
Practice \& Research. Clinical Endocrinology \& Metabolism, vol. 29, no. 2, pp. 183-194, 2015.

[86] K. Wyatt, W. Henley, L. Anderson et al., "The effectiveness and cost-effectiveness of enzyme and substrate replacement therapies: a longitudinal cohort study of people with lysosomal storage disorders," Health Technology Assessment, vol. 16, pp. 1-566, 2012.

[87] Y. Sato and T. Okuyama, "Novel enzyme replacement therapies for neuropathic mucopolysaccharidoses," International Journal of Molecular Sciences, vol. 21, no. 2, p. 400, 2020.

[88] A. Leone, D. Rigante, D. Z. Amato et al., "Spinal involvement in mucopolysaccharidoses: a review," Child's Nervous System, vol. 31, no. 2, pp. 203-212, 2015.

[89] J. Muenzer, C. J. Hendriksz, Z. Fan et al., “A phase I/II study of intrathecal idursulfase-IT in children with severe mucopolysaccharidosis II," Genetics in Medicine, vol. 18, no. 1, pp. 73-81, 2016.

[90] J. B. Eisengart, E. I. Pierpont, A. M. Kaizer et al., "Intrathecal enzyme replacement for Hurler syndrome: biomarker association with neurocognitive outcomes," Genetics in Medicine, vol. 21, no. 11, pp. 2552-2560, 2019.

[91] W. Tong, C. A. Dwyer, B. E. Thacker et al., "Guanidinylated neomycin conjugation enhances intranasal enzyme replacement in the brain," Molecular Therapy, vol. 25, no. 12, pp. 2743-2752, 2017.

[92] T. Okuyama, Y. Eto, N. Sakai et al., "Iduronate-2-sulfatase with anti-human transferrin receptor antibody for neuropathic mucopolysaccharidosis II: a phase 1/2 trial," Molecular Therapy, vol. 27, no. 2, pp. 456-464, 2019.

[93] Y. B. Sohn, A.-R. Ko, M.-r. Seong et al., "The efficacy of intracerebroventricular idursulfase-beta enzyme replacement therapy in mucopolysaccharidosis II murine model: heparan sulfate in cerebrospinal fluid as a clinical biomarker of neuropathology," Journal of Inherited Metabolic Disease, vol. 41, no. 6, pp. 1235-1246, 2018.

[94] R. Giugliani, L. Giugliani, F. de Oliveira Poswar et al., "Neurocognitive and somatic stabilization in pediatric patients with severe mucopolysaccharidosis type i after 52 weeks of intravenous brain-penetrating insulin receptor antibodyiduronidase fusion protein (valanafusp alpha): an open label phase 1-2 trial," Orphanet Journal of Rare Diseases, vol. 13, pp. 1-11, 2018.

[95] H. Fu and D. M. McCarty, "Crossing the blood-brain-barrier with viral vectors," Current Opinion in Virology, vol. 21, pp. 87-92, 2016.

[96] C. L. Christensen, R. E. Ashmead, and F. Y. M. Choy, “Cell and gene therapies for mucopolysaccharidoses: base editing and therapeutic delivery to the CNS," Diseases, vol. 7, no. 3, p. 47, 2019.

[97] L. Ou, M. J. Przybilla, O. Ahlat et al., "A highly efficacious PS gene editing system corrects metabolic and neurological complications of mucopolysaccharidosis type I," Molecular Therapy, vol. 28, no. 6, pp. 1442-1454, 2020.

[98] H. Ameri, "Prospect of retinal gene therapy following commercialization of voretigene neparvovec-rzyl for retinal dystrophy mediated by RPE65 mutation," Journal of Current Ophthalmology, vol. 30, pp. 1-2, 2018.

[99] N. J. Weinreb, J. A. Barranger, J. Charrow, G. A. Grabowski, H. J. Mankin, and P. Mistry, "Guidance on the use of miglustat for treating patients with type 1 Gaucher disease,"
American Journal of Hematology, vol. 80, no. 3, pp. 223229, 2005.

[100] E. Piotrowska, J. Jakóbkiewicz-Banecka, A. Tylki-Szymanska et al., "Genistin-rich soy isoflavone extract in substrate reduction therapy for Sanfilippo syndrome: an open-label, pilot study in 10 pediatric patients," Current Therapeutic Research, vol. 69, no. 2, pp. 166-179, 2008.

[101] A. Friso, R. Tomanin, M. Salvalaio, and M. Scarpa, "Genistein reduces glycosaminoglycan levels in a mouse model of mucopolysaccharidosis type II," British Journal of Pharmacology, vol. 159, no. 5, pp. 1082-1091, 2010.

[102] E. Piotrowska, J. Jakóbkiewicz-Banecka, S. Barańska et al., "Genistein-mediated inhibition of glycosaminoglycan synthesis as a basis for gene expression-targeted isoflavone therapy for mucopolysaccharidoses," European Journal of Human Genetics, vol. 14, no. 7, pp. 846-852, 2006.

[103] V. Delgadillo, M. Del Mar O’Callaghan, R. Artuch, R. Montero, and M. Pineda, "Genistein supplementation in patients affected by Sanfilippo disease," Journal of Inherited Metabolic Disease, vol. 34, no. 5, pp. 1039-1044, 2011.

[104] J. de Ruijter, M. Valstar, W. Kulik, F. Wijburg, and G. Wegrzyn, "Genistein in Sanfilippo disease: a randomized controlled cross-over trial," Molecular Genetics and Metabolism, vol. 105, no. 2, p. S26, 2012.

[105] E. Entchev, I. Jantzen, P. Masson et al., "Odiparcil, a potential glycosaminoglycans clearance therapy in mucopolysaccharidosis VI-evidence from in vitro and in vivo models," PLoS One, vol. 15, pp. 1-22, 2020.

[106] P. Arn, J. E. Wraith, and L. Underhill, "Characterization of surgical procedures in patients with mucopolysaccharidosis type I: findings from the MPS I Registry," The Journal of Pediatrics, vol. 154, no. 6, pp. 859-864.e3, 2009.

[107] K. Bhattacharya, S. C. Gibson, and V. L. Pathi, "Mitral valve replacement for mitral stenosis secondary to Hunter's syndrome," The Annals of Thoracic Surgery, vol. 80, no. 5, pp. 1911-1912, 2005.

[108] S. M. Haley, M. A. Fragala Pinkham, H. M. Dumas, P. Ni, A. M. Skrinar, and G. F. Cox, "A physical performance measure for individuals with mucopolysaccharidosis type I," Developmental Medicine and Child Neurology, vol. 48, no. 7, pp. 576-581, 2006.

[109] A. Soni-Jaiswal, J. Mercer, S. A. Jones, I. A. Bruce, and P. Callery, "Mucopolysaccharidosis I; parental beliefs about the impact of disease on the quality of life of their children," Orphanet Journal of Rare Diseases, vol. 11, no. 1-9, 2016.

[110] G. M. Pastores, P. Arn, M. Beck et al., "The MPS I registry: design, methodology, and early findings of a global disease registry for monitoring patients with mucopolysaccharidosis type I," Molecular Genetics and Metabolism, vol. 91, no. 1, pp. 37-47, 2007.

[111] R. Giugliani, A. Federhen, M. V. M. Rojas et al., "Mucopolysaccharidosis I, II, and VI: brief review and guidelines for treatment," Genetics and Molecular Biology, vol. 33, no. 4, pp. 589-604, 2010.

[112] I. V. Schwartz, M. G. Ribeiro, J. G. Mota et al., "A clinical study of 77 patients with mucopolysaccharidosis type II," Acta Paediatrica, vol. 96, pp. 63-70, 2007.

[113] S. C. Dusing, A. Rosenberg, J. R. Hiemenz, S. Piner, and M. Escolar, "Gross and fine motor skills of children with Hurler syndrome (MPS-IH) post umbilical cord blood 
transplantation: a case series report," Pediatric Physical Therapy, vol. 17, pp. 264-267, 2005.

[114] K. Viezel, J. Zibulsky, R. Dumont, and J. O. Willis, "Bayley scales of infant and toddler development, third edition," in Encyclopedia of Special Education, John Wiley \& Sons, Inc., 2014.

[115] C. H. Blauw-Hospers, T. Dirks, L. J. Hulshof, A. F. Bos, and M. Hadders-Algra, "Pediatric physical therapy in infancy: from nightmare to dream? A two-arm randomized trial," Physical Therapy, vol. 91, no. 9, pp. 1323-1338, 2011.

[116] S. Otman, N. Kose, and Y. Yakut, “The efficacy of Schroth's 3dimensional exercise therapy in the treatment of adolescent idiopathic scoliosis in Turkey," Neurosciences, vol. 10, no. 4, pp. 277-283, 2005.

[117] H. R. Weiss, "Rehabilitation of adolescent patients with scoliosis - what do we know? A review of the literature," Pediatric Rehabilitation, vol. 6, no. 3-4, pp. 183-194, 2009.

[118] G. Ebenbichler, A. Liederer, and W. Lack, "Scoliosis and its conservative treatment possibilities," Wiener medizinische Wochenschrift, vol. 144, no. 24, p. 593, 1994.

[119] C. Fusco, F. Zaina, S. Atanasio, M. Romano, A. Negrini, and S. Negrini, "Physical exercises in the treatment of adolescent idiopathic scoliosis: an updated systematic review," Physiotherapy Theory and Practice, vol. 27, no. 1, pp. 80-114, 2011.

[120] R. Marinela, "Early physical therapy intervention in infant hip dysplasia," Procedia - Social and Behavioral Sciences, vol. 76, pp. 729-733, 2013.

[121] S. C. Dusing, Physical therapy for children with MPS and related, National MPS society, 2006.

[122] L. A. Livingston, J. M. Stevenson, and S. J. Olney, "Stairclimbing kinematics on stairs of differing dimensions," Archives of Physical Medicine and Rehabilitation, vol. 72, no. 6, pp. 398402, 1991.

[123] Y.-W. Chae, J.-W. Park, and S. Park, "The Effect of postural stability on genu varum in young adults," Journal of Korean Physical Therapy, vol. 24, no. 6, pp. 419-422, 2012.

[124] M. N. Eek, R. Tranberg, R. Zügner, K. Alkema, and E. Beckung, "Muscle strength training to improve gait function in children with cerebral palsy," Developmental Medicine and Child Neurology, vol. 50, no. 10, pp. 759-764, 2008.

[125] E. Mohamed Abd El-Kafy and H. M. Y. M. El-Basatiny, "Effect of postural balance training on gait parameters in children with cerebral palsy," American Journal of Physical Medicine \& Rehabilitation, vol. 93, no. 11, pp. 938-947, 2014.

[126] N. Smania, P. Bonetti, M. Gandolfi et al., "Improved gait after repetitive locomotor training in children with cerebral palsy," American Journal of Physical Medicine \& Rehabilitation, vol. 90, no. 2, pp. 137-149, 2011.

[127] J. Machado and E. Seabra, "Design of an adapted standing frame for rehabilitation of children with mental deficiency," Romanian Review Precision Mechanics, Optics and Mechatronics, vol. 3, pp. 81-87, 2011.

[128] R. Mortimer, M. Privopoulos, and S. Kumar, "The effectiveness of hydrotherapy in the treatment of social and behavioral aspects of children with autism spectrum disorders: a systematic review," Journal of Multidisciplinary Healthcare, vol. 7, pp. 93-103, 2014.

[129] D. S. V. Hulls, L. K. Walker, and J. M. Powell, "Clinicians' perceptions of the benefits of aquatic therapy for young children with autism," Physical \& Occupational Therapy in Pediatrics, vol. 26, no. 1, pp. 13-22, 2006.
[130] B. I. Akinola, C. A. Gbiri, and D. O. Odebiyi, "Effect of a 10week aquatic exercise training program on gross motor function in children with spastic cerebral palsy," Global Pediatric Health, vol. 6, 2019.

[131] L. Cugusi, A. Manca, M. Bergamin et al., "Aquatic exercise improves motor impairments in people with Parkinson's disease, with similar or greater benefits than land-based exercise: a systematic review," Journal of Physiotherapy, vol. 65, no. 2, pp. 65-74, 2019.

[132] C. Hinderer, P. Bell, B. L. Gurda et al., "Liver-directed gene therapy corrects cardiovascular lesions in feline mucopolysaccharidosis type I," Proceedings of the National Academy of Sciences of the United States of America, vol. 111, no. 41, pp. 14894-14899, 2014.

[133] P. Methajarunon, C. Eitivipart, C. J. Diver, and A. Foongchomcheay, "Systematic review of published studies on aquatic exercise for balance in patients with multiple sclerosis, Parkinson's disease, and hemiplegia," Hong Kong Physiotherapy Journal, vol. 35, pp. 12-20, 2016.

[134] F. Mattosde, N. Leite, A. Pitta, and P. C. B. Bento, "Effects of aquatic exercise on muscle strength and functional performance of individuals with osteoarthritis: a systematic review," Revista Brasileira de Reumatologia (English Edition), vol. 56, pp. 530-542, 2016.

[135] W. Kamin, "Diagnosis and management of respiratory involvement in Hunter syndrome," Acta Paediatrica, vol. 97, pp. 57-60, 2008.

[136] K. I. Berger, S. C. Fagondes, R. Giugliani et al., "Respiratory and sleep disorders in mucopolysaccharidosis," Journal of Inherited Metabolic Disease, vol. 36, pp. 201-210, 2013.

[137] J. Muenzer, M. Beck, C. M. Eng et al., "Multidisciplinary management of Hunter syndrome," Pediatrics, vol. 124, 2009.

[138] L. P. S. Mendes, K. S. Moraes, M. Hoffman et al., "Effects of diaphragmatic breathing with and without pursed-lips breathing in subjects with COPD," Respiratory Care, vol. 64, pp. 136-144, 2019.

[139] A. P. F. F. Dualibi, A. M. Martins, G. A. Moreira, M. F. D. Azevedo, R. R. Fujita, and S. S. N. Pignatari, "Impacto do tratamento com laronidase nas manifestações otorrinolaringológicas de pacientes com mucopolissacaridose," Brazilian Journal of Otorhinolaryngology, vol. 82, pp. 522-528, 2016.

[140] B. Bordoni, F. Marelli, B. Morabito, and B. Sacconi, "Manual evaluation of the diaphragm muscle," International Journal of Chronic Obstructive Pulmonary Disease, no. 11, pp. 19491956, 2016.

[141] A. Tulebayeva, M. Sharipova, and R. Boranbayeva, "Respiratory dysfunction in children and adolescents with mucopolysaccharidosis types I, II, IVA, and VI," Diagnostics, vol. 10, pp. 1-8, 2020.

[142] T. Pitts, D. Bolser, J. Rosenbek, M. Troche, M. S. Okun, and C. Sapienza, "Impact of expiratory muscle strength training on voluntary cough and swallow function in Parkinson disease," Chest, vol. 135, no. 5, pp. 1301-1308, 2009.

[143] C. G. Summers, K. T. Fahnehjelm, S. Pitz et al., "Systemic therapies for mucopolysaccharidosis: ocular changes following haematopoietic stem cell transplantation or enzyme replacement therapy - a review," Clinical \& Experimental Ophthalmology, vol. 38, pp. 34-42, 2010.

[144] K. T. Fahnehjelm, J. L. Ashworth, S. Pitz et al., "Clinical guidelines for diagnosing and managing ocular 
manifestations in children with mucopolysaccharidosis," Acta Ophthalmologica, vol. 90, no. 7, pp. 595-602, 2012.

[145] L. Pinello, M. Busin, L. Fontana, and H. S. Dua, “Application of (lamellar) keratoplasty and limbal stem cell transplantation for corneal clouding in the mucopolysaccharidoses - a review," Clinical and Experimental Ophthalmology, vol. 38, pp. 52-62, 2010.

[146] M. E. Verdugo, V. Scarpino, P. Moullier, M. E. Haskins, G. D. Aguirre, and J. Ray, "Adenoviral vector-mediated Bglucuronidase cDNA transfer to treat MPS VII RPE in vitro," Current Eye Research, vol. 23, no. 5, pp. 357-367, 2009.

[147] A. E. Argenta and A. Davit, "Carpal tunnel syndrome in the setting of mucopolysaccharidosis II (Hunter syndrome)," Plastic and Reconstructive Surgery - Global Open, vol. 5, pp. 1-3, 2017.

[148] J.-Y. Kwon, K. Ko, Y. B. Sohn et al., "High prevalence of carpal tunnel syndrome in children with mucopolysaccharidosis type II (Hunter syndrome)," American Journal of Medical Genetics Part A, vol. 155, no. 6, pp. 1329-1335, 2011.

[149] F. S. Haddad, D. H. A. Jones, A. Vellodi, N. Kane, and M. C. Pitt, "Carpal tunnel syndrome in the mucopolysaccharidoses and mucolipidoses," The Journal of Bone and Joint Surgery. British Volume, vol. 79, no. 4, pp. 576-582, 1997.

[150] H. Terai and H. Nakamura, "Surgical management of spinal disorders in people with mucopolysaccharidoses," International Journal of Molecular Sciences, vol. 21, no. 3, p. 1171, 2020.

[151] A. E. Van Heest, J. House, W. Krivit, and K. Walker, "Surgical treatment of carpal tunnel syndrome and trigger digits in children with mucopolysaccharide storage disorders," The Journal of Hand Surgery, vol. 23, no. 2, pp. 236-243, 1998.

[152] J. E. Wraith and S. M. Alani, "Carpal tunnel syndrome in the mucopolysaccharidoses and related disorders," Archives of Disease in Childhood, vol. 65, no. 9, pp. 962-963, 1990.

[153] P. Bonanni, M. Gubernale, F. Martinez et al., "Non-convulsive status epilepticus of frontal origin in mucopolysaccharidosis type II successfully treated with ethosuximide," Developmental Medicine and Child Neurology, vol. 54, no. 10, pp. 961-964, 2012. 